\title{
Middle atmosphere effects of the quasi-two-day wave determined from a General Circulation Model
}

\author{
Scott E. Palo ${ }^{1}$, Raymond G. Roble ${ }^{2}$, and Maura E. Hagan ${ }^{2}$ \\ ${ }^{1}$ Department of Aerospace Engineering, University of Colorado, Boulder, CO 80309-0429, U.S.A. \\ ${ }^{2}$ National Center for Atmospheric Research, High Altitude Observatory, Boulder, CO 80307, U.S.A.
}

(Received August 24, 1998; Revised February 1, 1999; Accepted May 30, 1999)

\begin{abstract}
A set of numerical experiments have been conducted using the National Center for Atmospheric Research Thermosphere-Ionosphere-Mesosphere-Electrodynamics General Circulation Model (NCAR TIME-GCM) to understand the effects of the quasi-two-day wave (QTDW) on the middle atmosphere horizontal wind and temperature fields. A zonal wavenumber three perturbation with a period of 48 hours and a latitudinal structure identical to the $(3,0)$ Rossby-gravity mode has been included at the lower-boundary of the model. A response in the middle atmosphere horizontal wind fields is observed with a structure qualitatively similar to observations and other model results. There is also some evidence to suggest an increase in the lower-thermosphere QTDW response due to the interaction with gravity waves. Changes are observed in the zonal mean wind and temperature fields that are clearly related to the QTDW, however it is unclear if these changes are the direct result of wave driving due to the QTDW or are from another source. Evidence for nonlinear interactions between the QTDW and the migrating tides is presented. This includes significant (40-50\%) decreases in the amplitude of the migrating tides when the QTDW is present and the generation of wave components which can be tracked back to an interaction between the QTDW and the migrating tides. Clear evidence for the existence of a westward propagating zonal wavenumber six nonmigrating diurnal tidal component which results from the nonlinear interaction between the QTDW and the migrating tides is also presented.
\end{abstract}

\section{Introduction}

The quasi-two-day wave (QTDW) is a feature of the mesosphere and lower-thermosphere that has been observed from the ground and space over the past 25 years. Some of the earliest observations of the QTDW were made using meteor radars (Muller, 1972; Kal'chanko and Bulgakov, 1973; Clark, 1975) and indicated the presence of an oscillation in the lower-thermosphere (ca. $80-100 \mathrm{~km}$ ) with a period near 2 days. Numerous other radar measurements, mostly meteor and medium frequency, have been made of the QTDW in the horizontal wind field during the northern hemisphere summer (Salby and Roper, 1980; Tsuda et al., (1988); Clark, 1989; Clark et al., 1994; Fritts and Isler, 1994; Thayaparan et al., 1997a,b). These measurements indicate that the QTDW present in the northern hemisphere during the summer months has a period between 44 and 56 hours.

In addition to the early observations made in the northern hemisphere, Craig et al. (1980) and Craig and Elford (1981) published reports documenting the presence of the QTDW in the southern hemisphere. These measurements indicated the presence of a wave in the horizontal wind field with a period close to 48 hours which occurred in late January. Comparison of the zonal and meridional winds indicated a meridional wind field that was 2 to 3 times larger than the zonal. Similar results were found by Harris (1994) who analyzed 12 years of Adelaide data. This difference in amplitudes between the

Copy right $(\mathrm{C}$ The Society of Geomagnetism and Earth, Planetary and Space Sciences (SGEPSS); The Seismological Society of Japan; The Volcanological Society of Japan; The Geodetic Society of Japan; The Japanese Society for Planetary Sciences. zonal and meridional wind fields has also been observed in the northern hemisphere. Observations of the QTDW made in the equatorial region (Kal'chanko and Bulgakov, 1973; Coy, 1979; Harris and Vincent, 1993; Palo and Avery, 1995, 1996) reveal the presence of the QTDW during both austral and boreal summer. This indicates a penetration of the QTDW across the equator from the summer to winter hemisphere.

Some of the earliest ground-based observers (Glass et al., 1975; Craig et al., 1980) made an effort to estimate the zonal wavenumber of the QTDW using observations from multiple sites separated in longitude. These initial estimates concluded that the QTDW is a westward propagating zonal wavenumber three disturbance. More recently, again using ground-based radar observations, Meek et al. (1996) and Thayaparan et al. (1997b) have presented evidence for zonal wavenumbers 4 and 5 respectively, during the northern hemisphere summer.

To this point we have only highlighted the ground-based observations, however there have been numerous observations from space. Early temperature retrievals (Rodgers and Prata, 1981; Burks and Leovy, 1986) indicated the presence of the QTDW in the upper stratosphere with temperature perturbations from 0.2 to 0.6 Kelvin. These results also found that during January 1973 and January 1979 the QTDW was a westward propagating zonal wavenumber three disturbance. More recently numerous observations from the UARS spacecraft have reported on the presence of the QTDW in horizontal winds (Wu et al., 1993; Ward et al., 1996), temperature 
(Wu et al., 1995), and volume emission rate (Ward et al., 1996). These results are in keeping with previous results indicating that the QTDW is a westward propagating disturbance that occurs in the summer hemisphere with wavenumber 3 typically in January and wavenumber 3 and/or 4 in July/August. However these observations from space do provide a much more detailed picture of the latitudinal structure of the QTDW than could be determined solely from groundbased measurements.

Now, based upon the aforementioned observations there are a number of characteristics of the QTDW that become apparent. These are: 1) The QTDW is a regularly occurring feature of the summer lower-thermosphere; 2) In the southern hemisphere the period of the QTDW is close to 48 hours and almost always occurs near the end of January while in the northern hemisphere the wave period and time of occurrence are more variable; 3) The QTDW is a westward propagating disturbance with wavenumber 3 dominant in the southern hemisphere while wavenumbers 2-5 have been documented in the northern hemisphere; 4) The QTDW has been observed in winds, temperature and composition with the meridional winds typically larger than the zonal. Given these characteristics there are two theories relating to the generation and manifestation of the QTDW. These are the normal mode and instability theories. Salby (1981a,b) proposed that the QTDW is a manifestation of the gravest asymmetric westward propagating zonal wavenumber three normal mode. This is also referred to as the $(3,0)$ Rossby-normal mode. In an ideal atmosphere, defined by Laplace's tidal equation, the $(3,0)$ Rossby-mode is a natural unforced resonant solution with a period of 2.1 days which has a zonal wavenumber of three and propagates westward. Using a mechanistic model based upon the linearized perturbation equations Salby $(1981 \mathrm{a}, \mathrm{b})$ showed that the $(3,0)$ Rossby-normal mode will produce a significant response in the summer hemisphere. These simulations were based upon analytical background wind and temperature fields. Hagan et al. (1993), using realistic background winds, temperatures, and dissipation also found a similar response in the lowerthermosphere that compared favorably with observations.

The instability theory was first proposed by Plumb (1983) and subsequently pursued by Pfister (1985). Plumb (1983) and Pfister (1985), using one and two dimensional stability models, found that waves with periods between 1.5 and 3 days propagating westwards with zonal wavenumber from 2 to 4 could be generated from a baroclinic instability in the summer strato/mesospheric jet. Randel (1994), using NMC data, found a strong correlation between the occurrence of the QTDW and a change of sign in the latitudinal gradient of quasi-geostrophic potential vorticity $\left(\bar{q}_{y}\right)$ in the region near the summer strato/mesospheric jet. A change in the sign of $\bar{q}_{y}$ is a necessary but not sufficient condition for the onset of instability. Recent papers by Lieberman (1999) and Fritts et al. (1999) using observations from the HRDI (Hays et al., 1993) instrument on the UARS satellite, have also documented a change in sign of $\bar{q}_{y}$ during January 1992, 1993 and 1994 when the QTDW is present. More importantly, Lieberman (1999) estimated the Eliassen-Palm flux and flux divergence for the QTDW during January 1994 and found a region of divergence in the southern hemisphere mesosphere that coincided the region where $\bar{q}_{y}$ changes sign. These findings in addition to the meridional heat fluxes determined by Lieberman (1999) are consistent with the baroclinic instability hypothesis.

Given the modeling and observational evidence it appears that both the normal mode and instability hypotheses are consistent with the available data. Clearly neither of these mechanisms can be ruled out. In fact it has been proposed by Randel (1994) and Norton and Thuburn (1996) that the QTDW is connected to both of these mechanisms. The concept is that the structure of the zonal mean zonal wind is such that in the summer hemisphere waves can be generated via baroclinic instability. The waves generated via instability are expected to have a phase speed similar to the background zonal mean zonal flow in the region where the instability occurs. For the QTDW this is about $55 \mathrm{~m} \mathrm{~s}^{-1}$ which indicates that the waves generated via instability in this region would be propagating westward with a phase speed of $55 \mathrm{~m} \mathrm{~s}^{-1}$. The low zonal wavenumber waves with this phase speed are the W1 (westward zonal wavenumber 1) 6 day wave, the W2, 3 day wave, the $\mathrm{W} 3,2$ day wave, the $\mathrm{W} 4,1.5$ day wave, and so on. Now only the W3, 2 day wave is close to a resonant response of the atmosphere. With this the case it is conceivable that a baroclinic instability is providing the initial forcing of the QTDW that is followed by a normal mode response which is responsible for the large scale global response. Norton and Thuburn (1996) found in the UGAMP GCM that the initial structure of the QTDW was similar to an instability and as the response grew with time its structure approached that expect for a normal mode. Therefore, it appears that the initial transient response of the QTDW is the related to a baroclinic instability while the quasi-steady-state response is related to a normal mode.

In addition to the work mentioned above by Norton and Thuburn (1996) there has only been one other report of the QTDW in a global circulation model. This was by Hunt (1981) who observed a westward propagating zonal wavenumber three disturbance with a period near 2 days in the southern hemisphere during January. Hunt (1981) noted the wave was confined between 50 and $100 \mathrm{~km}$ altitude with a very small phase variation, indicative of a normal mode type response. In both these reports of the QTDW (Hunt, 1981; Norton and Thuburn, 1996) middle atmosphere GCMs were used which extend from the surface to approximately $100 \mathrm{~km}$. Because these models extend down into the stratosphere and troposphere they are quite useful for investigating the nature by which the QTDW is excited. However, the upper boundary is around $100 \mathrm{~km}$ therefore making it difficult to infer the effects above $85 \mathrm{~km}$ where the QTDW attains its largest amplitude.

It has been our goal, through the use of the NCAR TIMEGCM which extends from 35 to $800 \mathrm{~km}$, to understand how the QTDW can affect the middle and upper atmosphere winds, thermal structure, composition and electrodynamics. In this paper we will confine our discussions to the effects in the mesosphere and lower-thermosphere wind and thermal structure, while initial results from this work have been discussed in Palo et al. (1998). It should be noted that we have not made any effort to identify the forcing of the QTDW other than to say that a QTDW does not generate 
self-consistently within the model domain. Rather we force the lower-boundary of the TIME-GCM in a manner similar to Salby (1981a) and Hagan et al. (1993) to excite the normal mode type response in the model. One possibility for the lack of self-generation within the TIME-GCM model domain is that only large scale waves, such as the tides are included at the lower-boundary. It is possible that the lack of small scale perturbations at the model lower-boundary may hinder the excitation of an instability.

We present results, in the sections that follow, describing the middle atmospheric effects which occur when the lower-boundary of the TIME-GCM is perturbed with a $(3,0)$ Rossby-normal mode type structure. Our results indicate that the QTDW is interacting with the mean flow, tides and gravity waves. Each one of these interactions, in addition to a comparison with GSWM model results and observations of the QTDW will follow.

\section{The TIME-GCM}

The National Center for Atmospheric Research Thermosphere-Ionosphere-Mesosphere-Electrodynamics General Circulation Model (NCAR TIME-GCM) is a fully self-consistent time-dependent three-dimensional model of the Earth's atmosphere from approximately $35 \mathrm{~km}$ to $800 \mathrm{~km}$. The model simulates circulation, thermal structure, composition and electrodynamics on a $5^{\circ}$ by $5^{\circ}$ horizontal grid and 2 points per scale height in the vertical while the subgrid scale processes, such as gravity wave effects are parameterized. The current gravity wave parameterization used in the TIME-GCM is identical to that used by the NCAR Middle Atmosphere Community Climate Model (MA-CCM) (Boville, 1995; Kiehl et al., 1998). For more information on the TIMEGCM the reader is referred to Roble et al. (1988), Roble and Ridley (1994) and references therein.

The QTDW was excited at the lower boundary $(\sim 35 \mathrm{~km})$ of the TIME-GCM by perturbing the geopotential with a 48 hour westward propagating zonal wavenumber 3 disturbance with an amplitude of 160 meters and a latitudinal structure defined by the $(3,0)$-Rossby-normal mode. The model was run for 42 days, with the forcing present at the lower boundary for the first 30 days. An additional set of models runs was made without the QTDW forcing at the lower boundary and this serves as our control or base run. In the text that follows we will refer to difference fields. These difference fields are computed by subtracting the base result from the perturbed result for each output time step of the model. For the results presented herein the model output was saved every two hours.

Before the QTDW was excited in the TIME-GCM the subgrid scale processes were tuned to provide a zonal wind field that is consistent with observations for December solstice based on UARS observations (McLandress et al., 1996). Following this tuning the model was advanced to January 15, when the QTDW forcing was applied. The results presented herein are for a perpetual January 15.

A number of numerical experiments were conducted using the TIME-GCM to determine the sensitivity of the QTDW to the model forcing. These experiments included forcing the model for a December, January and February period in addition to modifying the lower-boundary forcing from a period of 48 hours to a period of 50 hours. In the case where the model was forced for both the December 15 and February 15 conditions, there was no appreciable response observed in the middle atmosphere. Only for the January 15 case was a significant response observed. One possible reason for the lack of a QTDW response in December and February is that the structure of the zonal mean winds do not support a quasiresonant response. This will be discussed in more in the sections that follow.

\section{Results}

Observations of the QTDW have indicated that its period is not exactly 48 hours but rather can range from 44 to 54 hours. However, during January the wave period appears to be the most stable. To determine the sensistivity of the QTDW response in the middle atmosphere to the wave period we forced the TIME-GCM at a period of 48 and 50 hours. The results of these experiments are described below.

Figure 1 shows the amplitude and phase that result when the technique of complex demodulation is applied to model results. The technique of complex demodulation can be used to provide an estimate of the "instantaneous" wave amplitude and period. This technique has been applied to one dimensional observational data (Harris, 1994; Palo and Avery, 1995) and can be simply extended to two-dimensional data. Herein we have utilized a two-dimensional complex demodulation technique in time and longitude to extract the zonal wavenumber three component. Defining the TIME-GCM output as $x(t, \lambda, \phi, z)$ then the demodulated signal $y_{\mathrm{d}}(t, \phi, z)$ is

$$
\begin{aligned}
& y_{\mathrm{d}}(t, \phi, z)=\frac{1}{\pi *\left(t_{b}-t_{a}\right)} \int_{t \in\left[t_{a}, t_{b}\right]} \int_{\lambda} x(t, \lambda, \phi, z) * \\
& \mathrm{e}^{-j *\left(\frac{2 \pi}{\omega_{0}} t-\frac{\pi s}{180} \lambda\right)} d \lambda d t
\end{aligned}
$$

where $t$ is time, $\lambda$ is longitude, $\phi$ is latitude, $z$ is altitude, $t_{a}$ and $t_{b}$ are integration times, $\omega_{\mathrm{o}}$ is the demodulation frequency and $s$ is the demodulation wavenumber. The integration in time and longitude is a lowpass filtering operation. By computing the zonal average, the component at wavenumber $s$ is extracted while the temporal averaging extracts the wave components around the frequency $\omega_{0}$. A long temporal averaging window will select components in a narrow bandwidth around $\omega_{\mathrm{o}}$ while a short temporal averaging window will select components in a wide bandwidth around $\omega_{\mathrm{o}}$. Roughly speaking the bandwidth is inversely related to the length of the temporal averaging window. Notice that $y_{\mathrm{d}}(t, \phi, z)$ is a complex valued function and as such it can be separated into an amplitude component $A(t, \phi, z)$ and a phase component $\Phi(t, \phi, z)$ where

$$
y_{\mathrm{d}}(t, \phi, z)=A(t, \phi, z) \mathrm{e}^{j \Phi(t, \phi, z)} .
$$

The estimated instantaneous wave amplitude is simply the amplitude component $A(t, \phi, z)$ while the estimated instantaneous wave period is inferred from the temporal derivative of the phase component $\omega(t, \phi, z)=\frac{\partial}{\partial t} \Phi(t, \phi, z)$.

The demodulated amplitude shown in Fig. 1 (top left) is for a lower boundary forcing with a period of 48 hours and maximizes at $96 \mathrm{~km}$ on day 14 between $42.5^{\circ} \mathrm{S}$ and $47.5^{\circ} \mathrm{S}$. The demodulated amplitude exhibits a structured initial response which subsides by day 5 and is most likely a transient 

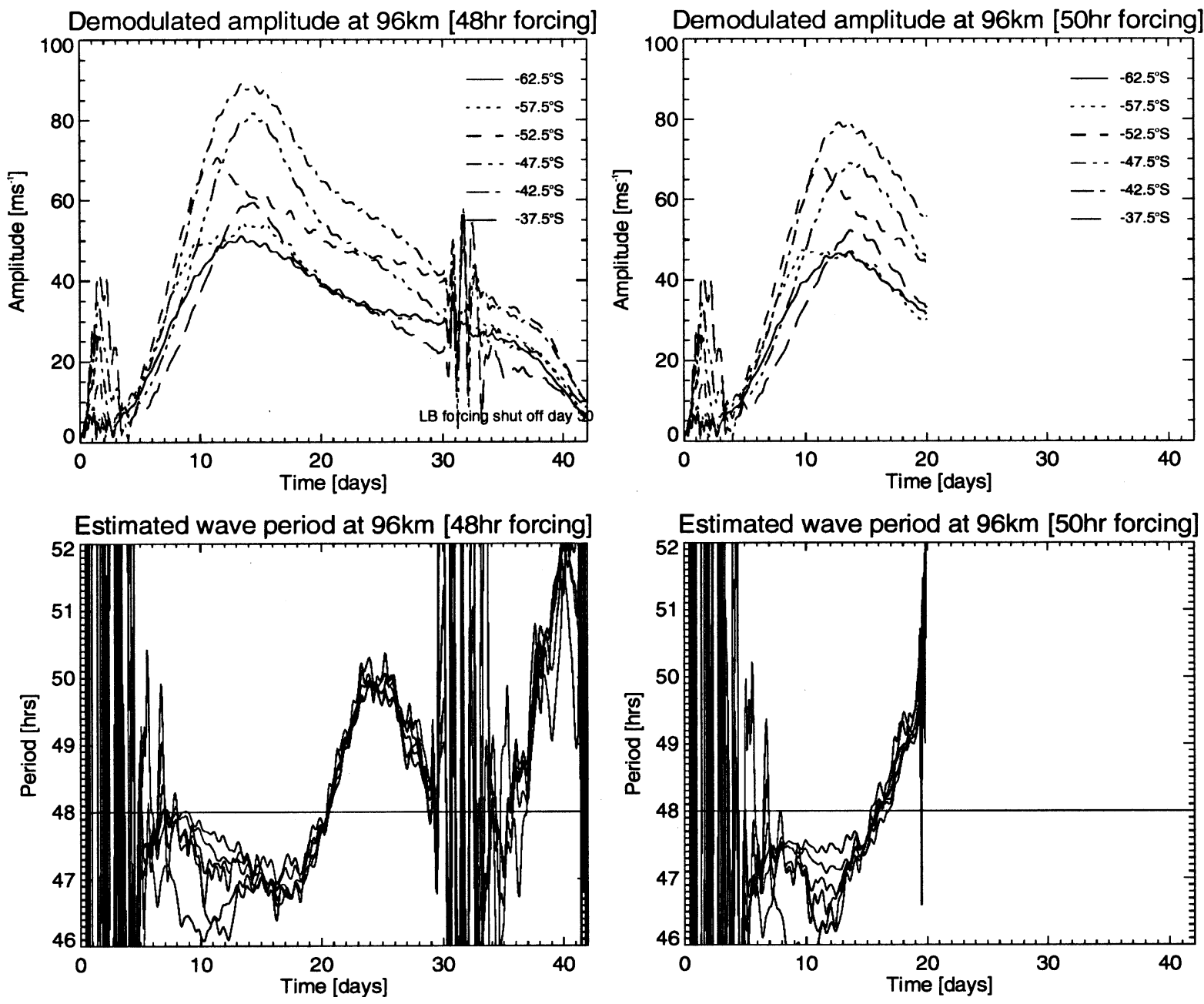

Fig. 1. Complex demodulation of the meridional wind field for a lower boundary forcing of 48 hours (left) and 50 hours (right). Multiple latitudes are show for an altitude of $96 \mathrm{~km}$. The amplitude of the quasi-two-day wave (top) and instantaneous wave period (bottom) are shown.

due to the stepwise nature in which the forcing was applied. After this transient the wave amplitude steadily increases to a maximum near $90 \mathrm{~m} \mathrm{~s}^{-1}$ on day 14 . From days 14 to 30 the wave amplitude decays with a perturbation present on days 30 to 33 which results when the lower boundary forcing was shut off. The amplitude structure is similar at all southern hemisphere latitudes presented in Fig. 1 with some minor differences in the growth and decay rates of the wave amplitude. Also shown in Fig. 1 (top right) is the QTDW amplitude when the lower boundary was perturbed using a wave period of 50 hours. For this case the model was only run for 20 days. The results for the 50 hour case are quantitatively similar to the case where a forcing at 48 hours was used. The only obvious difference is that when the lower boundary forcing was 48 hours the observed maximum amplitudes around day 14 are about $10 \mathrm{~m} \mathrm{~s}^{-1}$ larger then when the lower boundary forcing at 50 hours was used.

The bottom two panels of Fig. 1 show the estimated wave period for the two cases described above. Prior to day 6 there is no evidence for any coherent wave activity while between days 6 and 13 the wave period at the latitudes shown becomes more organized with excursions to periods near 46 hours. By day 14 the wave period for both cases shown converges indicating that the QTDW is latitudinally coherent after this time. For the case where the lower boundary is 48 hours the wave period lingers near a period of 47 hours until day 18 and then increases to a period near 50 hours on day 23 and in the process crosses a period of 48 hours on day 20. The wave period for the 50 hour case undergoes a similar evolution however this begins a few days earlier and crosses 48 hours on day 15.

By using a two-dimensional linear least squares fit to a period of 48 hours and a westward propagating wavenumber three (W3), it is possible to determine the vertical and latitudinal structure of the QTDW for any specified epoch. Figure 2 shows the vertical and latitudinal structure of the QTDW in the meridional wind field for the two cases where the lower boundary forcing is at 48 and 50 hours, for days 14 to 16 . As was the case for the amplitude structure of the complex demodulated signals the vertical and latitudinal structure of the QTDW in the meridional wind field are quite similar for the two cases. The only apparent difference is in the value of the peak amplitudes which are reduced by 10 to $15 \%$ in the case where a forcing at 50 hours is used.

The remainder of the results presented herein will be for the case where the lower boundary forcing was at 48 hours. 
TIME-GCM Meridional Wind, days 14-16 [48hr forcing]

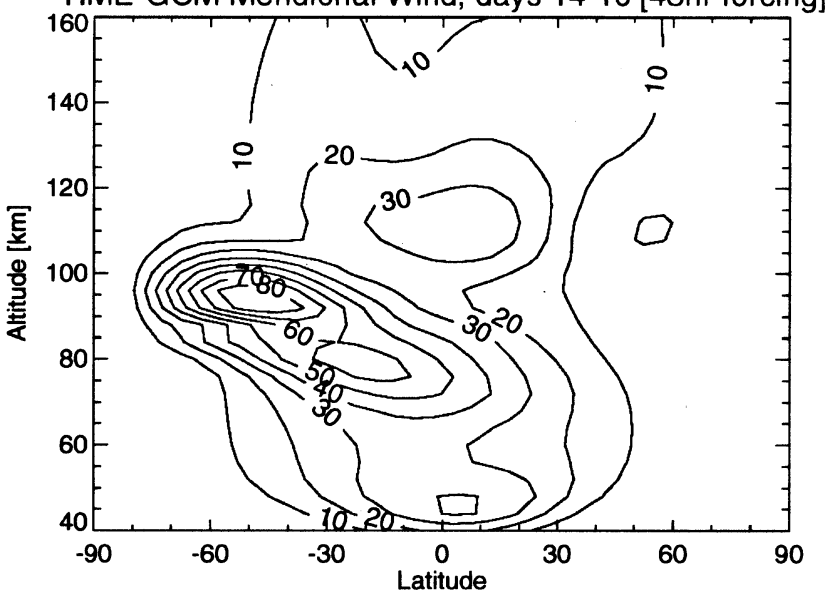

TIME-GCM Meridional Wind, days 14-16 [50hr forcing]

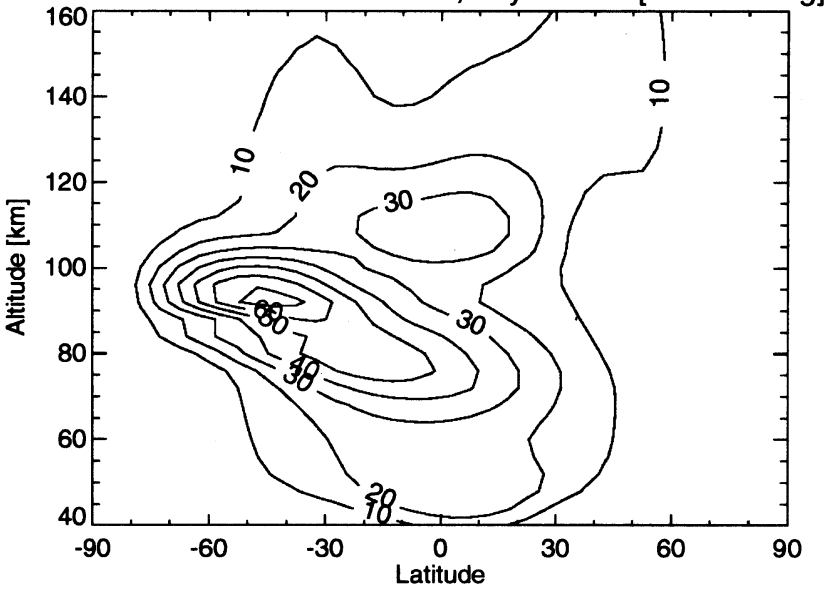

Fig. 2. The altitude and latitude structure of the quasi-two-day wave computed for days $14-16$ for a lower boundary forcing at 48 hours (top) and 50 hours (bottom).

\subsection{Quasi-two-day wave winds and temperature}

As was mentioned previously the TIME-GCM can provide estimates of numerous quantities in the middle and upper atmosphere relating to dynamics, composition and electrodynamics. For the purpose of this paper we will restrict ourself to the dynamical impacts of the QTDW on the horizontal wind and temperature fields.

Figure 3 shows results from our TIME-GCM runs for the horizontal wind and temperature fields from days 1416. Also shown in Fig. 3 are results from the Global Scale Wave Model (GSWM). GSWM is a 2-dimensional linearized model that has been described by Hagan et al. (1993, 1995, 1999). Briefly, it solves the linearized Navier-Stokes equations for tidal and planetary wave perturbations as a function of latitude and altitude for a specified wave periodicity and zonal wavenumber. Empirical models of zonal mean temperature and zonal wind are used to specify the GSWM background atmosphere. GSWM planetary wave calculations are based on the assumption that these perturbations are manifestations of waves known as normal modes in classical tidal theory (Hagan et al., 1993; Forbes et al., 1995). GSWM includes molecular and eddy diffusivity effects, and parameterizations for ion drag and Newtonian cooling effects.
The GSWM results shown in Fig. 3 are for a westward propagating zonal wavenumber 3 disturbance with a period near 48 hours. Because the GSWM is a 2-D linear model while the TIME-GCM is a 3-D nonlinear model we do not expect the results from both models to be identical, however the GSWM is expected to provide information regarding the linear response of the QTDW to the specified background atmosphere. For the results shown in Fig. 3 the background zonal winds were taken from our TIME-GCM model runs for day 0 and the background temperature profile was take from MSISE-90 (Hedin, 1991). Previous studies of the QTDW (Hagan et al., 1993) have indicated that the impact of the zonal mean zonal winds far exceeds that of the zonal mean temperature, therefore use of the MSISE-90 results rather than self-consistent temperatures will have little if any impact on our results.

Comparison of the amplitude of the QTDW in the meridional wind field from Fig. 3 for the GSWM and TIME-GCM are similar in that the largest response occurs in the southern hemisphere lower-thermosphere. This is consistent with observations, however there are differences. Before discussing these differences it should be mentioned that because the forcing of the QTDW is unknown the models cannot be absolutely calibrated. For the GSWM an arbitrary forcing is applied to the lower boundary of the model and then all of the results are scaled by a single multiplicative factor to provide a meridional wind amplitude in the lower-thermosphere which is consistent with observations. This is possible because the GSWM is a linear model. For the TIME-GCM we conducted a number of numerical experiments whereby the magnitude of the forcing at the lower boundary was modified. We choose a geopotential height amplitude at the lowerboundary of $160 \mathrm{~m}$ for the QTDW which provides reasonable wave amplitudes in the lower-thermosphere. Because the TIME-GCM is a nonlinear model it is possible that small changes in the amplitude of the lower-boundary forcing could induce large changes elsewhere in the output domain. Our experience in tuning the lower boundary condition did not indicate that this is the case when the magnitude of the lower boundary forcing is around $160 \mathrm{~m}$.

As was mentioned above, there are a number of significant differences between the QTDW results provided from the GSWM and the TIME-GCM. In the meridional wind field the GSWM indicates the maximum wave amplitudes occur around $75 \mathrm{~km}$ near $30^{\circ} \mathrm{S}$ with a broad response which extends from $60^{\circ} \mathrm{S}$ to $25^{\circ} \mathrm{N}$ in the mesosphere and lowerthermosphere. In contrast the TIME-GCM results indicate a maximum wave amplitude in the meridional wind field around $95 \mathrm{~km}$ and $50^{\circ} \mathrm{S}$. However, if one follows the $50 \mathrm{~m} \mathrm{~s}^{-1}$ contour it descends in latitude and altitude encompassing the region of maximum amplitude found in the GSWM results. A second feature that is more pronounced in the TIME-GCM meridional wind field than the GSWM results is a region of enhanced wave amplitude directly over the equator in the lower-thermosphere (ca. 110-120 km). We believe this feature to be the result of gravity waves interacting with the QTDW. Because the GSWM is a linear model, this type of wave/wave interaction is not present and we would not expect to see a significant peak in the GSWM results. We further discuss the possibility of nonlinear QTDW and 

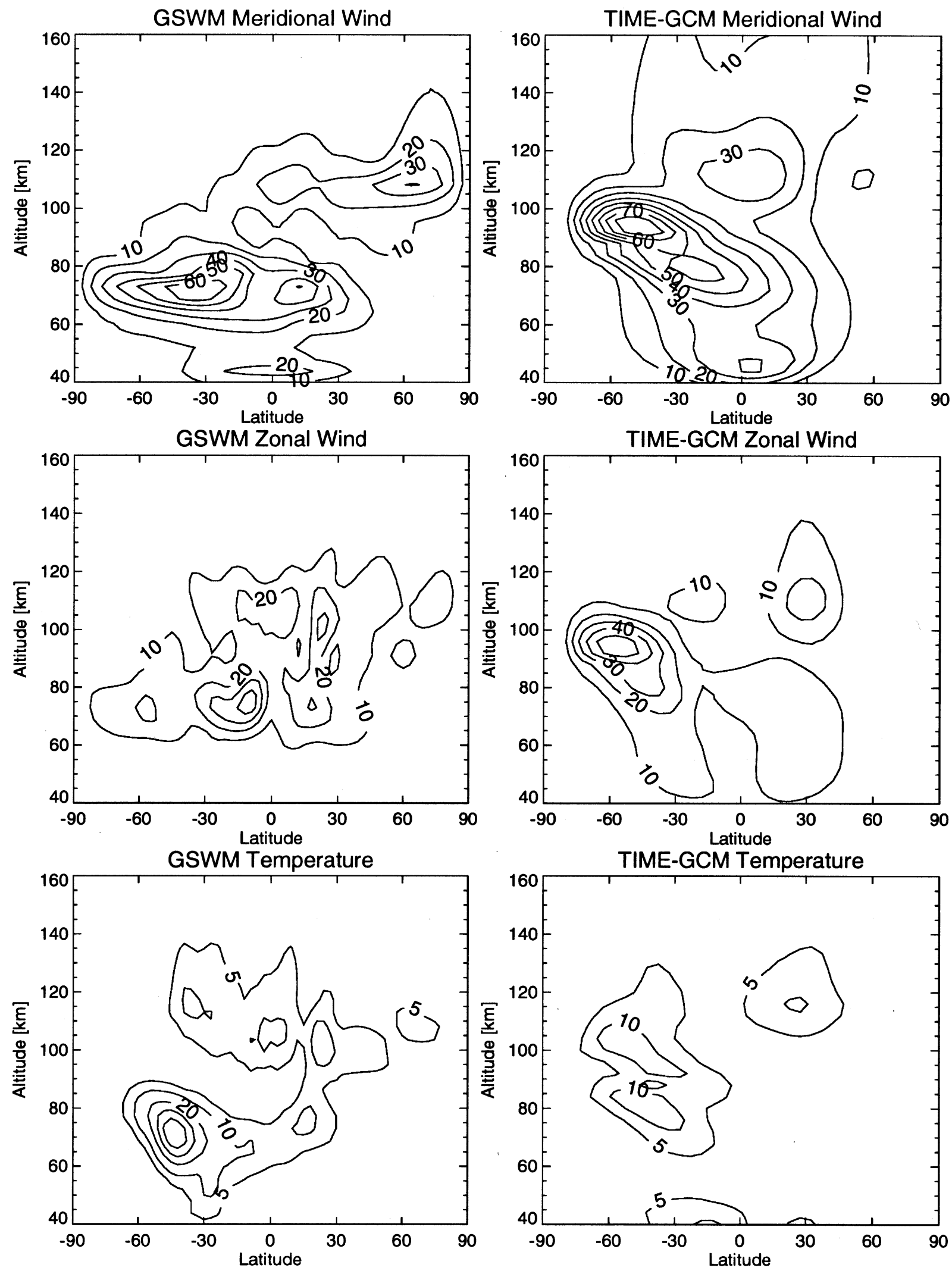

Fig. 3. The meridional wind amplitude (top), zonal wind amplitude (middle) and temperature (bottom) structure for the quasi-two-day wave inferred from the GSWM (left) and the TIME-GCM (right). 
gravity wave interactions below.

The GSWM and TIME-GCM zonal wind fields shown in Fig. 3 both indicate a large region of weak QTDW amplitudes throughout the mesosphere and lower-thermosphere. The largest amplitudes observed for the QTDW in the zonal wind field for both the GSWM and TIME-GCM results are nearly coincident with the meridional wind maximum. The TIMEGCM results do not show the same lower-thermosphere enhancement over the equator that was observed in the meridional wind field.

Comparison of the QTDW temperature fields for the GSWM and the TIME-GCM indicates some significant differences. The most obvious difference is the large mesospheric enhancement of / gt $40 \mathrm{~K}$, seen in the GSWM results at mid southern latitudes. This feature is not seen in the TIME-GCM results, rather two overlaying enhancements of $10 \mathrm{~K}$ are seen near $80 \mathrm{~km}$ and $100 \mathrm{~km}$ at mid southern latitudes. An additional enhancement is observed in the GSWM results at $110 \mathrm{~km}(15 \mathrm{~K})$ at $35^{\circ} \mathrm{N}$. This enhancement is also observed in the TIME-GCM results with an amplitude of $10 \mathrm{~K}$.

There have been numerous ground and spaced based observations of the QTDW reported, as was previously mentioned. While the ground-based observations provide good temporal information, there is no spatial information available. Therefore, in assessing the model results we have relied most heavily on satellite observations (Wu et al., 1993, 1996; Ward et al., 1996). The one exception is the work of Palo et al. (1997) where both ground and UARS data were available for an extensive 10-day campaign period. The UARS (Wu et al., 1993; Ward et al., 1996; Palo et al., 1997) results for the QTDW during January 1993 indicate a broad latitudinal structure with increased meridional amplitudes near $55^{\circ} \mathrm{S}$ and at the equator with amplitudes of 50 to $70 \mathrm{~m} \mathrm{~s}^{-1}$. The results from both the GSWM and TIME-GCM capture the mid-southern latitude structure, however the increased amplitude at the equator between 90 and $105 \mathrm{~km}$ is not apparent. Wu et al. (1996) has presented temperature measurements of the QTDW for January 1993 obtained from MLS instrument located on the UARS satellite. These measurements are from 22 to $73 \mathrm{~km}$ and therefore it is difficult to validate our measurements above this altitude. However, Wu et al. (1996) find a temperature maximum in the upper mesosphere of $5.5 \mathrm{~K}$ near $40^{\circ} \mathrm{S}$ at $73 \mathrm{~km}$. Because this is the top of their domain and the temperature contours have not closed it is possible that the temperature could keep increasing with altitude. Comparison of these measurements with the model results appear to indicate magnitudes more similar to the TIME-GCM results than the GSWM results. Both the TIME-GCM and GSWM results indicate a maximum response at midlatitudes in the southern hemisphere, similar to the observations. However, around $70 \mathrm{~km}$ the TIME-GCM shows a temperature perturbation of $8 \mathrm{~K}$ while the GSWM shows $30 \mathrm{~K}$. In this sense the TIME-GCM results appear to be more consistent with the UARS observations. This result may indicate that either time-dependent or nonlinear effects are important for the temperature structure of the QTDW. Neither of these are included in the GSWM.

One difficulty in comparing the TIME-GCM QTDW results to satellite observations is that in the case of the satellite observations the zonal mean zonal winds, during the period when the QTDW was strong, are not available. This results from the slow precession of the satellite. Without precise knowledge of the true zonal mean zonal winds during the observation period it is difficult to determine if the differences between the model results and observations only result from differences in the zonal mean zonal winds or if other processes are playing a role. The observations of $\mathrm{Wu}$ et al. (1993) do indicate a reasonable amount of interannual variability for the QTDW thus indicating that in comparison with the TIME-GCM results, we should expect some differences. Furthermore, 12 years of observations over Adeilaide (Harris, 1994) clearly exhibits a significant degree of interannual variability associated with the QTDW. The most obvious difference between the model results and observations is the lack of an equatorial response in the horizontal wind field for the model results. To date it is unclear as to why the models do not show the presence of an equatorial response. The most likely candidate is the zonal mean zonal winds, but this needs to be investigated more thoroughly.

Figure 4 shows the vertical structure of the QTDW in temperature and the horizontal wind fields from the TIME-GCM observed at $57.5^{\circ} \mathrm{S}$ and $2.5^{\circ} \mathrm{N}$. This was determined using a linear least squares fit to a period of 48 hours and a westward zonal wavenumber 3 for days 14-16. In both amplitude plots the temperature perturbation has been multiplied by four to aid in readability. The amplitudes observed at $57.5^{\circ} \mathrm{S}$ in the horizontal wind field are similar in structure with a maximum amplitude of $80 \mathrm{~m} \mathrm{~s}^{-1}\left(55 \mathrm{~m} \mathrm{~s}^{-1}\right)$ observed for the meridional (zonal) wind field at $95 \mathrm{~km}$. The vertical structure of the temperature perturbation at this latitude is bimodal with peaks at $82 \mathrm{~km}$ and $105 \mathrm{~km}$, and amplitudes from 10 to $15 \mathrm{~K}$. The phase structure in regions where there is a significant QTDW suggests a vertical wavelength close to $200 \mathrm{~km}$. Vertical wavelengths of 50 to $150 \mathrm{~km}$ have been typically quoted from measurements. These estimates have large errors as observations are only typically made over 20 to $30 \mathrm{~km}$. Here we have defined phase to indicate the longitude where the wave attains its maximum amplitude at 0 UT on the first day of the fit (day 14). The amplitude structure of the QTDW at $2.5^{\circ} \mathrm{N}$ is clearly different from the amplitude structure observed at $57.5^{\circ} \mathrm{S}$. First the wave amplitudes for all three fields are reduced with the maximum meridional (zonal) amplitude near $50 \mathrm{~m} \mathrm{~s}^{-1}\left(20 \mathrm{~m} \mathrm{~s}^{-1}\right)$. Additionally the vertical structure of the meridional amplitude indicates local maxima near $43 \mathrm{~km}$, $75 \mathrm{~km}$, and $115 \mathrm{~km}$ which is in contrast to the single maximum observed at $57.5^{\circ} \mathrm{S}$. It is likely that the increased amplitude in the meridional wind field at $43 \mathrm{~km}$ is a boundary effect as this is only a scale height from the lower boundary. Examination of the phase for the other two peaks, $-40^{\circ}$ at $75 \mathrm{~km}$ and $20^{\circ}$ at $115 \mathrm{~km}$, is half a wave period indicating that these two peaks are out-of-phase. A similar situation is observed for the quasi-biennial (Andrews et al., 1987) and the semiannual (Hirota, 1978; Dunkerton, 1982; Palo and Avery, 1993) oscillations where the mesospheric/lower-thermospheric maximum is out-of-phase with the stratospheric maximum. In the case of the semiannual oscillation (SAO) the stratospheric winds are preferentially filtering upward propagating gravity waves such that during the eastward phase of the SAO westward propagating gravity waves can penetrate into the 

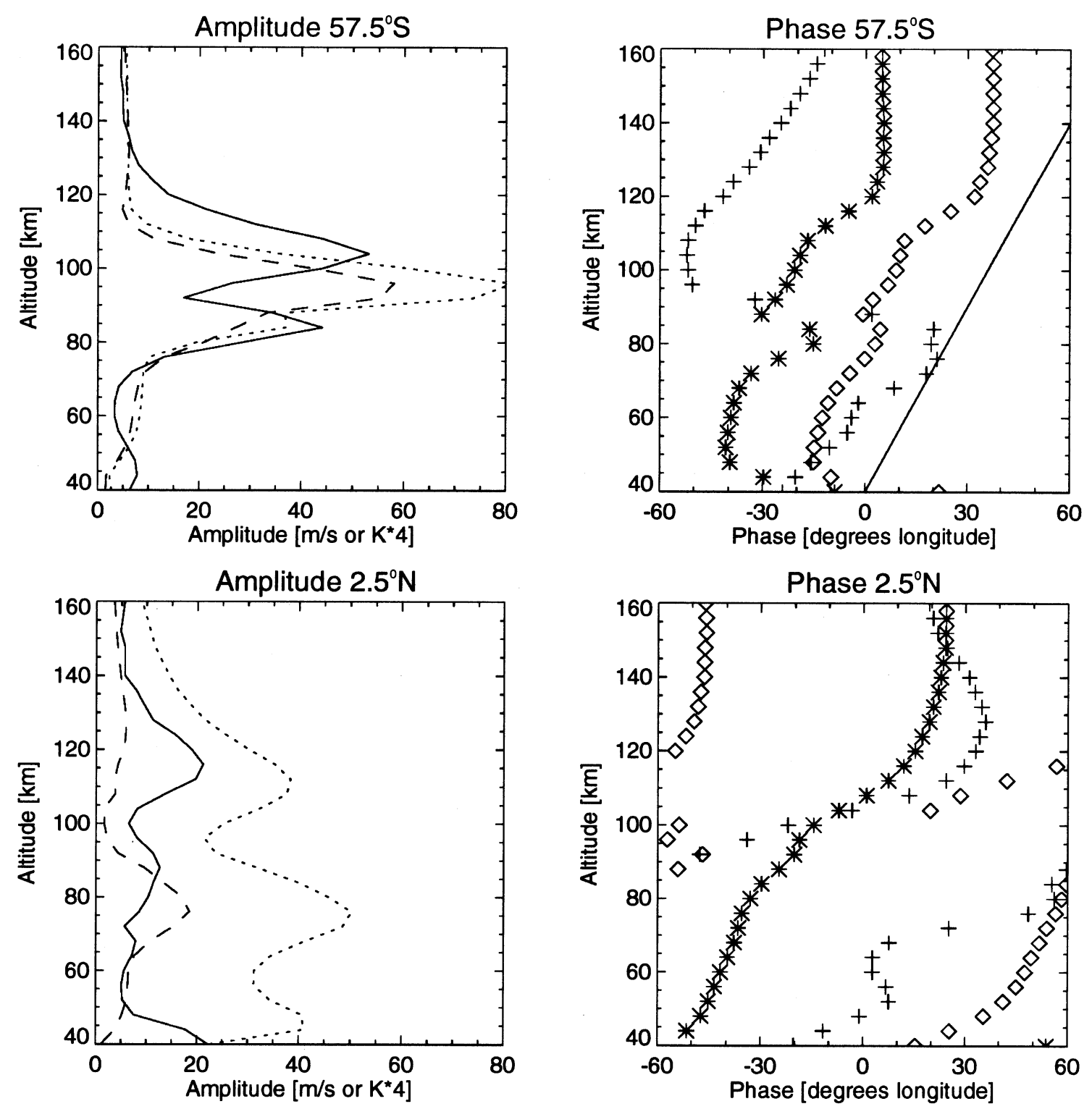

Fig. 4. The vertical structure of the quasi-two-day wave at a latitude of $57.5^{\circ} \mathrm{S}$ (top) and $2.5^{\circ} \mathrm{N}$ (bottom) from the TIME-GCM. The amplitude (left) and phase (right), defined as longitude of maximum at 0 UT, are shown for the meridional wind field (dot, asterisk), zonal wind field (dash, diamond) and temperature*4 (solid, cross). The solid line shown on the phase plot for $57.5^{\circ} \mathrm{S}$ indicates a $200 \mathrm{~km}$ vertical wavelength.

mesosphere and deposit momentum driving a westward circulation. During the eastward phase of the SAO the opposite is true. The result of this interaction is a SAO in the mesosphere/lower-thermosphere that is out-of-phase with the SAO in the stratosphere. It is plausible that a similar effect is occurring with the QTDW. In essence the QTDW in the mesosphere is selectively filtering upward propagating gravity waves. The result is a QTDW in the lowerthermosphere where the gravity waves are depositing their momentum that is out-of-phase with the QTDW in the mesosphere. Recent studies by Meyer (1994) using the GSWM have indicated that interactions between the QTDW and gravity waves are possible. Meyer (1994) found that when gravity waves were allowed to interact with the QTDW a peak in the meridional response of the QTDW appears in the lowerthermosphere similar to what is observed in the TIME-GCM results. This peak has been attributed to the interaction be- tween the QTDW and gravity waves by Meyer (1994). There is also observational evidence for the existence of a lowerthermospheric peak in the QTDW response. Both Ward et al. (1996) and Zhou et al. (1997) have observed a secondary peak in the QTDW response. Ward et al. (1996) presented WINDII observations from the UARS satellite that show a QTDW response which peaks near $90 \mathrm{~km}$ for the meridional (zonal) component with an amplitude of $40 \mathrm{~m} \mathrm{~s}^{-1}$ (10$30 \mathrm{~m} \mathrm{~s}^{-1}$ ) at mid-southern hemisphere latitudes. Above this peak there is a secondary peak around $115 \mathrm{~km}(110 \mathrm{~km})$ for the meridional (zonal) wind component with amplitudes near $20 \mathrm{~m} \mathrm{~s}^{-1}\left(10 \mathrm{~m} \mathrm{~s}^{-1}\right)$. The phase difference between the two peaks is about 15 hours for the meridional wind field and is quite variable for the zonal wind field. This phase difference only constitutes about a quarter of a wavelength compared to the half wavelength difference found in the TIME-GCM results. 


\subsection{Changes in the zonal mean winds}

It has been pointed out by Lieberman (1999) that the QTDW violates conditions for nonacceleration and therefore it is possible that the QTDW can modify the zonal mean zonal winds and temperatures. Loosely speaking, for linear or steady flows, wave perturbations do not interact with the mean state. However, transient waves, such as the QTDW, do violate the nonacceleration theorem (Charney and Drazin, 1961) and therefore they can modify the mean state of the atmosphere. In the following section results from our model runs, which indicate that changes in the zonal mean winds and temperatures do occur, are presented.

Figure 5 shows the changes in the zonal mean zonal winds, meridional winds and temperature from days 0-2 to days 14-16 when the QTDW is present. Almost no change is observed in these fields for the our base run where the QTDW is not present. The most dramatic changes are found in the zonal mean zonal wind field. The top row of Fig. 5 shows the time average zonal mean zonal winds computed for days 0 to 2 (left), days 14 to 16 (middle) and the difference between these two fields (right). Changes in the zonal mean zonal winds of $20 \mathrm{~m} \mathrm{~s}^{-1}$, both westward and eastward acceleration, are observed throughout the lower-thermosphere with the largest changes present equatorward of $60^{\circ}$. One peculiar feature of this difference field is its banded structure with alternating regions of westward and eastward acceleration. These regions of eastward and westward acceleration undergo a $180^{\circ}$ phase shift between 90 and $95 \mathrm{~km}$ such that regions of eastward acceleration overlie regions of westward acceleration and vice-versa. While the high latitude changes present in the zonal mean zonal winds are trapped below 120 $\mathrm{km}$, in the southern hemisphere mid to low latitudes and near the equator changes in the zonal mean zonal winds penetrate above $160 \mathrm{~km}$.

The temporally averaged zonal mean meridional winds are shown in the middle row of Fig. 5 for days 0 to 2 (left), days 14 to 16 (middle) and the difference between these two fields (right). The mean meridional circulation indicates a weak northward flow throughout the mesosphere and penetrating into the lower-thermosphere. A wind reversal to southward flow occurs between 100 and $120 \mathrm{~km}$, which is a function of latitude increasing in altitude from south to north. This region of southward flow is approximately $20 \mathrm{~km}$ thick and attains a maximum velocity of $7 \mathrm{~m} \mathrm{~s}^{-1}$. The most prominent feature in the meridional circulation is the strong northward flow $\left(15 \mathrm{~m} \mathrm{~s}^{-1}\right)$ present at high southern latitudes between 80 and $90 \mathrm{~km}$. This feature is directly related to the cold summer mesopause whereby gravity waves drive the atmosphere adiabatically from radiative equilibrium. This drives a mean meridional and vertical circulation (Andrews et al., 1987). The temporally averaged zonal mean meridional winds for days 14-16 have evolved, where the extent of the strong northward flow has expanded and the region of southward winds in the lower-thermosphere has become suppressed. Examination of the difference field indicates a weakening of the northward flow below the region of the north/south reversal in the lower-thermosphere with the exception of a strong northward enhancement near $90 \mathrm{~km}$ centered around the midlatitudes in the southern hemisphere. This region of northward acceleration is bounded above and below by regions of southward acceleration. These regions of northward/southward acceleration exceed $10 \mathrm{~m} \mathrm{~s}^{-1}$ and indicate an average meridional acceleration on the order of $1 \mathrm{~m} \mathrm{~s}^{-1}$ day $^{-1}$. Above the lower-thermospheric meridional reversal the changes to the zonal mean meridional wind field are northward with amplitudes near $5 \mathrm{~m} \mathrm{~s}^{-1}$.

Changes are also observed in the temporally averaged zonal mean temperature field shown in the bottom row of Fig. 5. The presentation for the temperature field is identical to the zonal mean zonal and meridional wind fields. Obvious in the temperature difference field is a change of 25 to $30 \mathrm{~K}$ in the region of the southern hemisphere mesopause. A strong cooling is observed between 90 and $95 \mathrm{~km}$ with smaller regions of warming observed above $(>100 \mathrm{~km})$ and below $(<85 \mathrm{~km})$. This cooling represents as much as a $30 \%$ change in the mesopause temperature. An additional region of cooling is also present over the equator that extends upwards from $100 \mathrm{~km}$. Because of the increase in thermospheric temperature with altitude these changes of 10 to $15 \mathrm{~K}$ only represent a percent or two change in temperature. These temperature changes should be measureable from either ground or spacebased instruments.

Because of the difficulty in measuring the global zonal mean winds and temperature, there have only be a limited number of studies documenting the effect of the QTDW on the mean state of the atmosphere. The first of these studies (Plumb et al., 1987), found that the QTDW could induce northward and westward accelerations in the mean state that were consistent with observations. More recently, Lieberman (1999) and Fritts et al. (1999) have investigated the effects of the QTDW on the zonal mean state using observations from UARS. The results of Lieberman (1999) are qualitatively consistent with Plumb et al. (1987) and indicate the QTDW can induce a northward and westward flow in the zonal mean wind fields. Zonal mean amplitudes of $1 \mathrm{~m} \mathrm{~s}^{-1}$ and $20-30 \mathrm{~m} \mathrm{~s}^{-1}$ were observed for the meridional and zonal winds respectively, while regions of heating and cooling from -3 to $+4.5 \mathrm{~K}$ were inferred. Our TIME-GCM results indicate somewhat more complicated results, with both eastward and westward acceleration observed in the zonal mean winds and northward and southward accerleration observed in the meridional mean winds. One possibility for these differences is that Lieberman (1999) computed the zonal mean wind changes due solely to the QTDW. This computation of the wave driving was not determined directly from observations rather a 2-D linear quasigeostrophic model was used to determine the wave driving due to the QTDW while the observations were used to guide the model input. The changes presented herein, from our TIME-GCM runs, include not only the direct wave driving due to the QTDW but also changes which result from the interaction between the QTDW and gravity waves in addition to those due to the transport and redistribution of long-lived species. Work is currently underway to separate these effects in an effort to understand more precisely how the QTDW is modifying the zonal mean state.

\subsection{Interactions with the migrating tides}

In recent years the subject of tidal variability has received significant attention. Observations from both ground (Avery et al., 1989; Manson et al., 1989; Vincent et al., 1989; Clark 

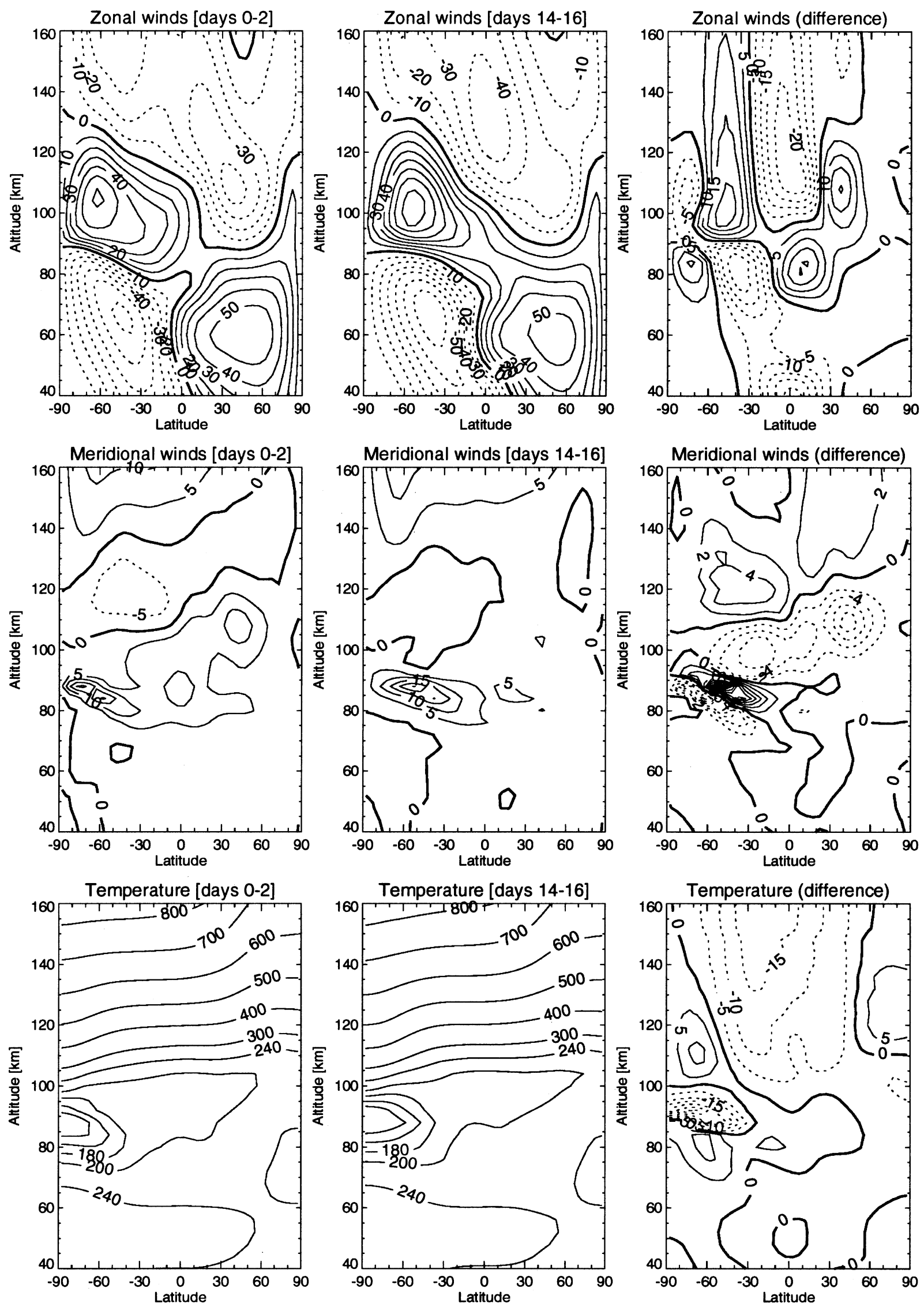

Fig. 5. The zonal mean zonal winds (top), zonal mean meridional winds (middle row) and zonal mean temperature are shown for days $0-2$ (left), days 14-16 (middle column) and the difference between days 0-2 and days 14-16 (right). 

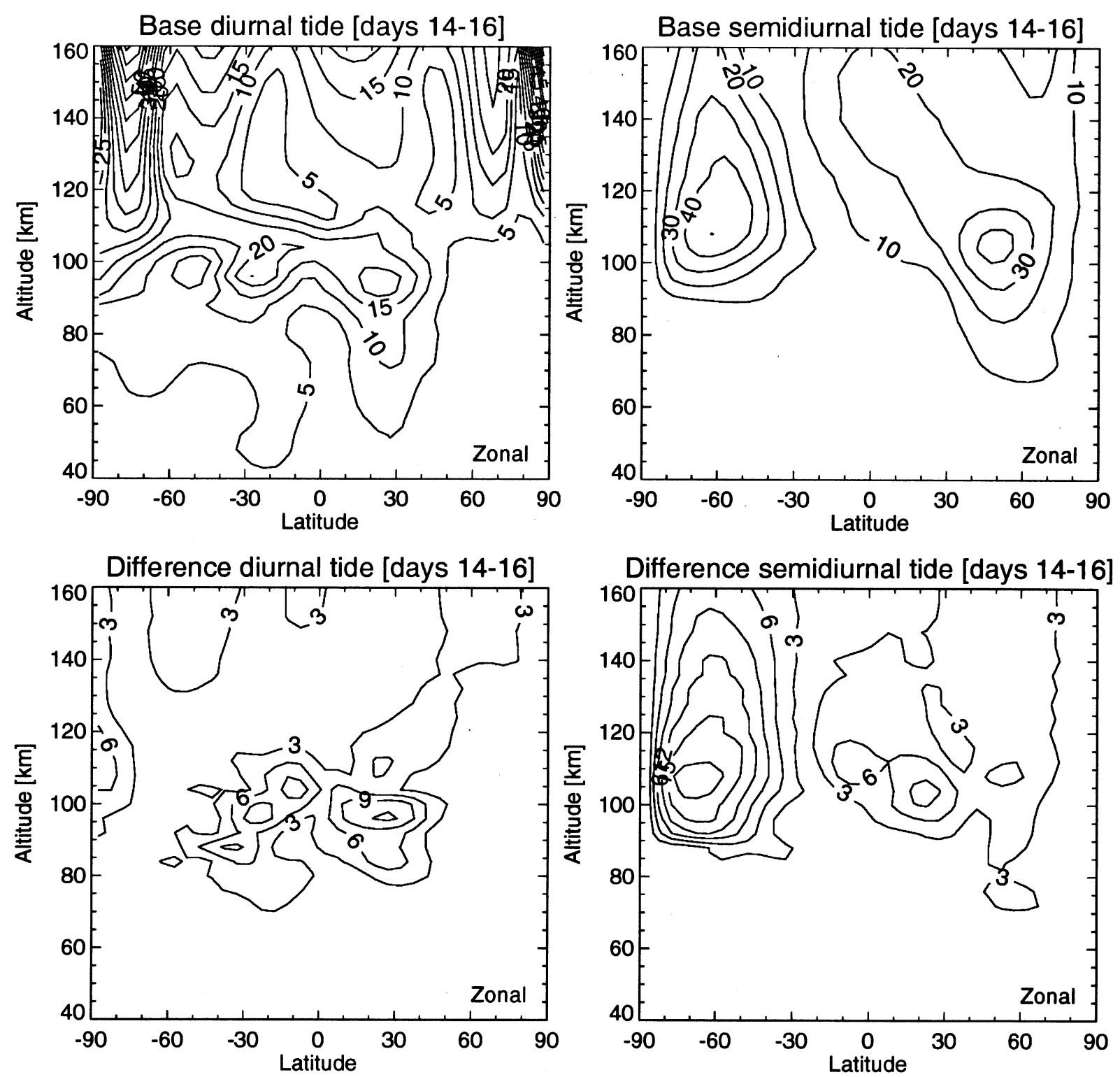

Fig. 6. The amplitude of the diurnal tide (left) and semidiurnal tide (right) in the zonal wind field are shown for days $14-16$ in the base case results (top) and the magnitude of the vector difference between the base and perturbed case (bottom).

and Salah, 1991; Fritts and Isler, 1994) and space (Hays et al., 1993; McLandress et al., 1994) have indicated that both the diurnal and semidiurnal tides can vary on time-scales of days to years. However, the interpretation of these observations is complicated due to the incomplete sampling that is inherent to each technique. For example a single ground based site cannot separate the migrating from the non-migrating tides while satellite observations have significant difficulty extracting the migrating tides. Given these limitations it is still clear from the observations that the structure of the migrating tides changes with time. The following sources have been proposed as possible mechanisms contributing to tidal variability; changes in the zonal mean winds, changes in the tidal forcing which include the global distribution of ozone, water vapor and the release of latent heat (Hagan, 1996; Hagan et al., 1997), variations in eddy diffusivity or dissipation (Geller et al., 1997; Yudin et al., 1997) and non-linear in- teractions between the tides and other planetary scale waves (Teitelbaum and Vial, 1991).

It is possible to use our TIME-GCM simulations of the QTDW to investigate the non-linear interactions between the QTDW and the migrating tides. Figure 6 shows the vertical and latitudinal structure of the migrating diurnal (left) and semidiurnal (right) tides in the zonal wind field. The top row of Fig. 6 illustrates the structure of the tides averaged over days 14-16 for our base case run (w/o QTDW). The amplitude structure of the tides is determined from a twodimensional linear least squares fit to a $24 \mathrm{hr}$, W1 component for the migrating diurnal tide and a $12 \mathrm{hr}$, W2 component for the migrating semidiurnal tide. It should be noted that the upward propagating semidiurnal and diurnal tides presented herein are specified at the lower boundary of the TIME-GCM. The value of the tidal amplitudes and phases at this level are taken from the GSWM results for the migrating semidiurnal 
and diurnal tide. No modification of the lower-boundary tidal amplitudes is necessary with the gravity wave scheme utilized for these model runs.

The structure of the diurnal tide in the zonal wind field shown in Fig. 6 (top left) is in agreement with observations and other modeling results with a mesospheric/lowerthermospheric peak in tidal amplitude near $95 \mathrm{~km}$ around $25^{\circ}$ north and south latitude. Above $110 \mathrm{~km}$ the in-situ diurnal tide becomes evident with increasing amplitudes in the polar regions. The zonal component of the migrating semidiurnal tide (top right) attains its maximum amplitudes in the lower-thermosphere between 100 and $120 \mathrm{~km}$. These maxima occur at mid to high latitudes with amplitudes in excess of $40 \mathrm{~m} \mathrm{~s}^{-1}$. For both the diurnal and semidiurnal tidal results there is evidence of hemispheric asymmetry in the tidal amplitudes.

Using the TIME-GCM results for the case where the QTDW is forced at the lower-boundary, difference fields were computed for the migrating tides. As was mentioned earlier, these difference fields were computed for each output time-step of the model and then the resulting multidimensional timeseries was analyzed in an identical manner as the base case results. Apparent in the differences fields, illustrated in Fig. 6, are changes on the order of $50 \%$ $\left(12 \mathrm{~m} \mathrm{~s}^{-1}\right)$ for the migrating diurnal tide (bottom left) and $40 \%\left(18 \mathrm{~m} \mathrm{~s}^{-1}\right)$ for the migrating semidiurnal tide. In both of these cases the tidal amplitudes are reduced when the QTDW is present. The most significant reduction in the migrating diurnal tide occurs near $95 \mathrm{~km}$ in the northern hemisphere tropics with changes on the order of $6 \mathrm{~m} \mathrm{~s}^{-1}$ evident throughout the $100 \mathrm{~km}$ region in both hemispheres extending from the equator to midlatitudes. Similarly the migrating semidiurnal tide exhibits reduced amplitudes, however the largest effects are confined to mid and high southern latitudes between 100 and $120 \mathrm{~km}$. This is the region where the migrating semidiurnal tide attains its maximum amplitude. There is also some evidence for a reduction in the migrating semidiurnal amplitude on the order of $9 \mathrm{~m} \mathrm{~s}^{-1}$ in the tropical northern latitudes around $110 \mathrm{~km}$.

Because the only difference between our two sets of TIMEGCM runs is the inclusion of the QTDW at the lower boundary, then we can conclude that this change in the amplitude of the migrating tides is directly related to the QTDW. There are a number of ways in which the QTDW could modify the structure of the QTDW both directly and indirectly. We have shown that there are significant changes in the structure of the zonal mean winds and temperatures when the QTDW is present. This could either directly affect the vertical propagation of the migrating tides or affect the vertical penetration of gravity waves into the mesosphere and lower-thermosphere. Changing the gravity wave field would in turn change the wave stress on the tides thereby modifying their amplitude structure. While both of these scenarios are possible they are not expected to induce significant changes in the structure of the tides. A more probable explanation is that the migrating tides are interacting non-linearly with the QTDW. Such an interaction would reduce the tidal amplitude while producing other planetary scale waves.

While the linearized perturbation equations are a reasonable first order approximation for the structure of planetary scale waves, when wave amplitudes become large the second order nonlinear effects begin to play a significant role in the wave structure. These effects arise from nonlinear interactions that occur in the advective terms of the momentum and thermodynamic equations (Teitelbaum and Vial, 1991). Such interactions appear as an amplitude modulation, and if the two waves interacting are sufficiently close in frequency then distinct supplementary waves will appear in the wave spectrum. The mathematical fundamentals underlying this process are quite simple and can be expressed using simple algebra. For example consider the two fields $x_{1}(t, \lambda)=$ $\cos \left(\omega_{1} t-s_{1} \lambda+\phi_{1}\right)$ and $x_{2}(t, \lambda)=\cos \left(\omega_{2} t-s_{2} \lambda+\phi_{2}\right)$. Now the multiplicative interaction between $x_{1}(t, \lambda)$ and $x_{2}(t, \lambda)$ yields

$$
\begin{aligned}
& x_{1}(t, \lambda) x_{2}(t, \lambda)= \\
& \quad \cos \left(\omega_{1} t-s_{1} \lambda+\phi_{1}\right) \cos \left(\omega_{2} t-s_{2} \lambda+\phi_{2}\right) \\
& =\alpha \cos \left(\left(\omega_{1}+\omega_{2}\right) t-\left(s_{1}+s_{2}\right) \lambda+\left(\phi_{1}+\phi_{2}\right)\right) \\
& +\beta \cos \left(\left(\omega_{1}-\omega_{2}\right) t-\left(s_{1}-s_{2}\right) \lambda+\left(\phi_{1}-\phi_{2}\right)\right),
\end{aligned}
$$

where $\alpha$ and $\beta$ are efficiency factors. From Eq. (3) we see that the nonlinear interaction between two waves results in two new distinct waves. We will refer to the interacting waves as the parent waves and the resulting waves as the child waves. If the interacting wave fields consist of a wave plus a nonzero mean then the resulting fields will consist of the child waves plus the parent waves, however the amplitude of the parent waves will be reduced as they have transferred some of their energy to the child waves. The two child waves that resulted from the nonlinear interaction in Eq. (3) are referred to as sum and difference waves. The frequency and wavenumber of the sum wave is $\omega_{\mathrm{s}}=\omega_{1}+\omega_{2}$ and $s_{\mathrm{s}}=s_{1}+s_{2}$ while the frequency and wavenumber for the difference wave is $\omega_{\mathrm{d}}=\omega_{1}-\omega_{2}$ and $s_{\mathrm{d}}=s_{1}-s_{2}$. If the two interacting waves have significantly different periods then the resulting sum and difference periods will be closer to the shorter of the two primary periods. For example the diurnal tide ( 24 hours) interacting with the 16 day wave will produce child waves at 22.5 and 25.6 hours while the semidiurnal tide (12 hours) interacting with the QTDW (48 hours) will produce child waves at 16 hours and 9.6 hours. This is important because in the case of the diurnal tide and the 16 day wave the child waves will appear as sidebands of the diurnal tide, which complicates the interpretation, while child waves which are reasonably separated from their parent waves are easier to interpret.

To this point we have supposed that the reason for the reduction in tidal amplitudes is a nonlinear interaction between the QTDW and the migrating tides. To further substantiate this supposition we present Fig. 7. Figure 7 shows the frequency-wavenumber spectra for the zonal wind field at $7.5^{\circ} \mathrm{N}$ and $100 \mathrm{~km}$ computed using a two-dimensional Fourier transform. Spectra are shown for the base case (left) and the case where the lower boundary is perturbed by the QTDW (right). In both spectra the maximum values have been normalized to one and the contour levels are $0.5,0.1$, and 0.01 . These correspond to amplitude values of $0.7,0.3$ and 0.1 , or $70 \%, 30 \%$ and $10 \%$ of the maximum amplitude value. The base spectra, shown in Fig. 7, indicates a simple wave field in the zonal winds consisting only of the migrat- 

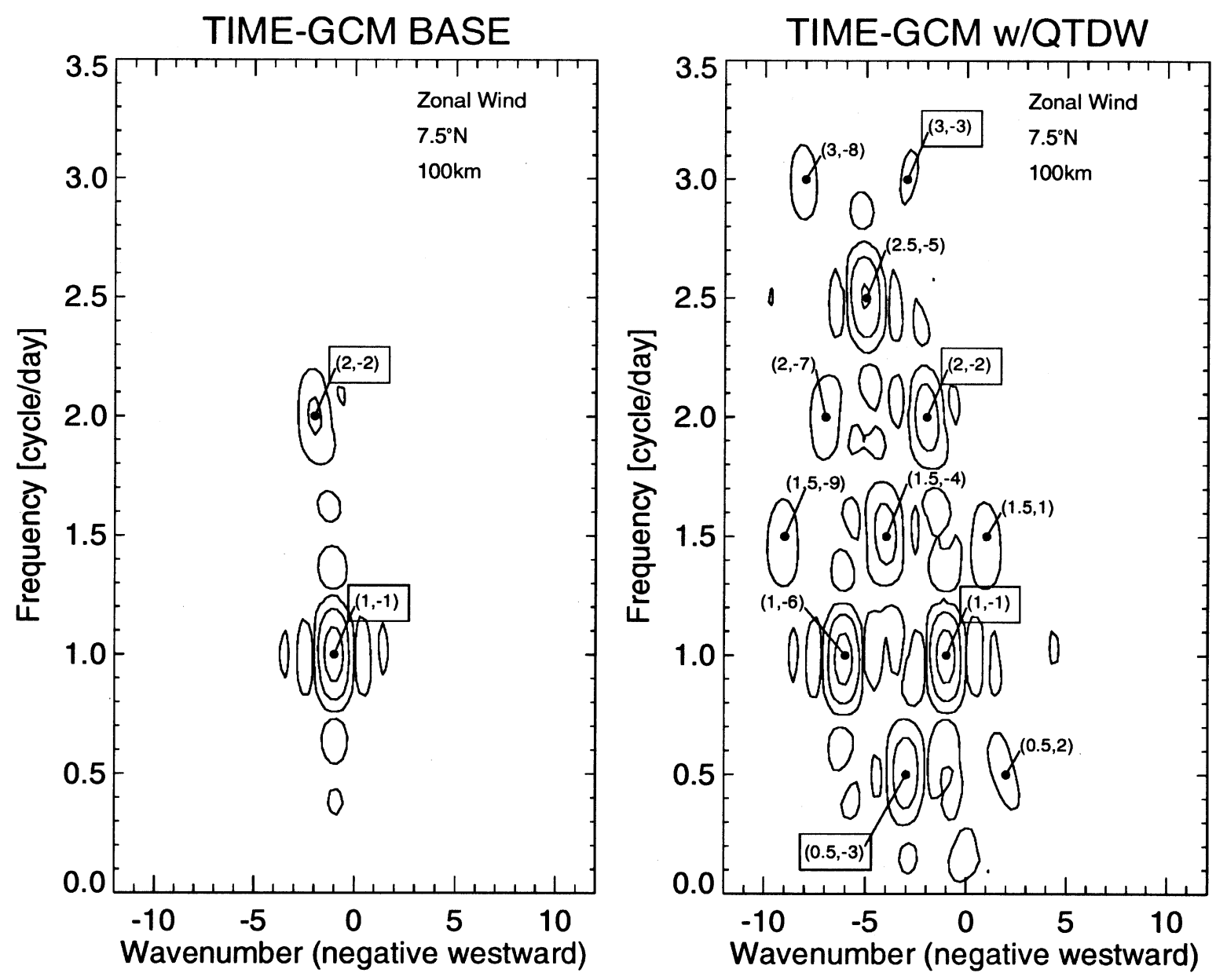

Fig. 7. Frequency-wavenumber spectra are shown for the base case (left) and perturbed case (right) zonal wind field at $100 \mathrm{~km}, 7.5^{\circ} \mathrm{N}$, and days $14-16$.

ing diurnal ( $1 \mathrm{cpd}, \mathrm{W} 1)$ and the migrating semidiurnal tide ( 2 cpd,W2). We have used the abbreviation cpd to indicate cycles per day. The smaller peaks located along W1 and a frequency of $1 \mathrm{cpd}$ are sidelobes of the migrating diurnal tide which arise because we are analyzing a finite length data set in both time and longitude. The amplitude of these peaks could be reduced by applying a window function to the data such as a Hamming or Kaiser window, however this would decrease our frequency resolution. Because our interest is in accurately identifying the location of the dominant peaks in the spectra we have not applied any taper function to the data. In describing the components in the frequency-wavenumber spectra we shall use the notation (frequency, wavenumber) where frequency is listed in cycles per day (cpd) and zonal wavenumbers are described using an alphanumeric pair (i.e. W3, westward propagating zonal wavenumber three) where $\mathrm{W}$ indicates westward propagating waves (negative in the spectra), while E indicates eastward propagating waves (positive in the spectra). The conversion from frequency in cpd to period in hours is $p=\frac{24}{f(c p d)}$.

When the QTDW is included at the lower-boundary of the TIME-GCM the spectrum of waves present in the zonal wind field becomes significantly more complex. The waves indicated by the rectangular boxes in Fig. 7, represent those wave, such as the migrating tides, that were present in the base case run or waves, or the QTDW which was specifically forced in the model. The remainder of the waves present in the spectra are self-generated within the model domain. It is clear by comparison of the two frequency-wavenumber spectra that these additional wave components present in the spectra are related to the presence of the QTDW.

Table 1 lists the wave components that appear in the frequency-wavenumber spectra when the QTDW is present in the TIME-GCM run that do not appear when the QTDW is not present. With the exception of the $(3, \mathrm{~W} 3)$ component, none of the other components can be generated by a nonlinear interaction between tidal components. However, all of these remaining wave components can be tracked back to an interaction between the QTDW and the migrating tides.

The child waves that result from a nonlinear interaction between the QTDW and the migrating diurnal tide are (1.5, W4) and $(0.5$, E2), while the child waves that result when the QTDW interacts with the semidiurnal tide are $(2.5, \mathrm{~W} 5)$ and $(1.5$, E1). Notice that all of these wave components are present in Table 1. These four child waves that result from an interaction between primary waves are referred to as 1-1 or one-step nonlinearities. The notation 1-1 indicates that both of the parent waves are primary waves. Now if a child wave and a primary wave interact this will result in a 1-2 or multistep nonlinearity. The notation 1-2 indicates that a first 
Table 1. Frequency and wavenumbers that are present in the TIME-GCM zonal winds w/QTDW at $7.5 \mathrm{degN}$ and $100 \mathrm{~km}$ that are not present $\mathrm{w} / \mathrm{o}$ QTDW.

\begin{tabular}{cc}
\hline Frequency(cpd)/Period(hrs) & Zonal wavenumber \\
\hline $0.5 / 48$ & $\mathrm{E} 2$ \\
$1.0 / 24$ & $\mathrm{~W} 6$ \\
$1.5 / 16$ & $\mathrm{~W} 9$ \\
$1.5 / 16$ & $\mathrm{~W} 4$ \\
$1.5 / 16$ & $\mathrm{E} 1$ \\
$2.0 / 12$ & $\mathrm{~W} 7$ \\
$2.5 / 9.6$ & $\mathrm{~W} 5$ \\
$3.0 / 8.0$ & $\mathrm{~W} 3$ \\
$3.0 / 8.0$ & $\mathrm{~W} 8$ \\
\hline
\end{tabular}

generation and second generation parent wave are interacting to produce a child wave. The child wave will be referred to as a third generation wave and is defined to be one generation younger than its youngest parent. For example a 3-4 or 4-4 interaction would yield a fifth generation child wave.

Interaction between each of the second generation waves yields a group of 2-2 third generation waves. These are the $(4.0, \mathrm{~W} 4)$ and $(1.0, \mathrm{~W} 6)$ which are generated from the $(2.5, \mathrm{~W} 6)$ and the $(1.5, \mathrm{E} 1)$ in addition to the $(2.0, \mathrm{~W} 2)$ and $(1.0, \mathrm{~W} 6)$ that are generated from the $(1.5, \mathrm{~W} 4)$ and the $(0.5, \mathrm{E} 2)$. Notice that both of these interactions generate a (1.0, W6) wave, which is listed in Table 1 . The actual spatial structure of the $(1.0$, W6) will depend upon the vector superposition of both of these resultant third generation waves. We discuss the $(1.0, \mathrm{~W} 6)$ in more detail below as it has been hypothesized to be the mechanism for locking the QTDW to local time and the sudden increase in QTDW amplitudes that has been observed. Also generated is a $(2.0, \mathrm{~W} 2)$ wave that is identical to the solar forced migrating solar semidiurnal tide. This component can either reinforce or reduce the amplitude of the migrating semidiurnal tide depending upon its phase relative to the migrating semidiurnal tide.

The remaining wave components present in Table 1 all appear to be fourth generation 1-3 type nonlinear interactions. For example the $(1.5, \mathrm{~W} 9)$ is the sum mode from the interactions between the QTDW and the (1.0, W6) which also produces a $(0.5, \mathrm{~W} 3)$ component as a difference mode. The $(2.0, \mathrm{~W} 7)$ can be produced from an interaction between the $(1.5, \mathrm{~W} 4)$ and the QTDW which will yield a (1.0, W1) while the $(3.0, \mathrm{~W} 8)$ may be the result of a nonlinear interaction between the $(2.5, \mathrm{~W} 5)$ and the QTDW which also yields a (2.0, W2). While the results are not definitive there does appear to be significant circumstantial evidence that the waves listed in Table 1 result from one- and multi-step nonlinearities between the migrating tides and the QTDW.

The frequency-wavenumber spectra presented in Fig. 7 provides some indication of the waves which may arise due to nonlinear interactions between the migrating tides and the QTDW. The vertical and latitudinal structure of the zonal wind field for the second generation 1-1 type nonlinear in- teractions between the migrating tides and the QTDW are shown in Fig. 8. These fields were determined using a twodimensional linear least squares fit to the specified frequency and wavenumber. Only the amplitude fields are shown however similar diagnostics for the phases have been computed. The two child waves generated from the interaction of the migrating diurnal tide and the QTDW are shown in the top row of Fig. 8, these are the (1.5, W4) (top left) and the $(0.5, \mathrm{E} 2)$ (top right). Of these two components the $(1.5, \mathrm{~W} 4)$ attains the largest zonal wind amplitudes in the northern hemisphere subtropics $\left(10^{\circ}-20^{\circ} \mathrm{S}\right)$ around $100 \mathrm{~km}$ with amplitudes of $12 \mathrm{~m} \mathrm{~s}^{-1}$. Amplitudes in excess of $8 \mathrm{~m} \mathrm{~s}^{-1}$ are present in the 90 to $110 \mathrm{~km}$ region from $60^{\circ} \mathrm{S}$ to $30^{\circ} \mathrm{N}$. The $(0.5, \mathrm{E} 2)$ attains amplitudes of $6-8 \mathrm{~m} \mathrm{~s}^{-1}$ in the southern hemisphere subtropics near $105 \mathrm{~km}$, with amplitudes of 2-4 $\mathrm{m} \mathrm{s}^{-1}$ elsewhere in the lower-thermosphere. The presence of this $(0.5$, E2) wave presents some interesting implications for the interpretation of both ground and satellite based observation of the QTDW. In the context of ground-based observations, the superposition of the $(0.5, \mathrm{E} 2)$ with the QTDW $(0.5, \mathrm{~W} 3)$ will produce longitudinal variations in the structure of the QTDW as viewed from the ground. This is similar to the difficulty encountered with the analysis of the migrating and non-migrating tides (see Palo et al. (1997) for an overview of this issue). The issue from a space-based observational platform is somewhat different. It turns out, serendipitously, that when single node data from a low Earth orbiting satellite, such as UARS, is analyzed the $(0.5, \mathrm{~W} 3)$ and the $(0.5$, E2) are "Doppler twins" (Salby, 1982). This means that in this case the two signals cannot be separated and the result of single node analysis for the $(0.5, \mathrm{~W} 3)$ will be the vector sum of the $(0.5, \mathrm{~W} 3)$ and the $(0.5, \mathrm{E} 2)$ in addition to other higher order aliases. Here single node data denotes that data from only a single latitude crossing per orbit is used, for example only daytime or only ascending node data. If dual node data (both ascending and descending data) is utilized then half of the aliases will be removed from the resulting analysis and this will include the $(0.5, \mathrm{E} 2)$. Therefore in the case where multiple node data is used the $(0.5, \mathrm{E} 2)$ will not contaminate the QTDW results.

Of all the second generation waves excited by the interaction of the migrating tides with the QTDW, the $(2.5, \mathrm{~W} 5)$ is the largest. Amplitudes in excess of $18 \mathrm{~m} \mathrm{~s}^{-1}$ are found in the lower-thermosphere (ca. $100-130 \mathrm{~km}$ ) near $30^{\circ} \mathrm{N}$ and $35^{\circ} \mathrm{S}$. There is evidence for a hemispheric asymmetry in this field with the maximum amplitudes occurring higher in latitude and altitude in the southern hemisphere. This wave field also penetrates deeper into the thermosphere than either of the other fields with amplitudes in excess of $6 \mathrm{~m} \mathrm{~s}^{-1}$ present above $150 \mathrm{~km}$. The $(1.5, \mathrm{E} 1)$, that results from the interaction of the QTDW with the migrating semidiurnal tide attains its largest amplitudes in the midlatitude lower-thermosphere region. The maximum amplitude of $6 \mathrm{~m} \mathrm{~s}^{-1}$ is found near $40^{\circ} \mathrm{S}$ and $120 \mathrm{~km}$ with regions where the amplitude exceeds $4 \mathrm{~m} \mathrm{~s}^{-1}$ present between 90 and $125 \mathrm{~km}$ in the southern hemisphere and 110 to $160 \mathrm{~km}$ in the northern hemisphere.

There has been little evidence for the presence of nonlinearly generated waves in observational data. This is primarily due to the fact that it is difficult to extract these wave components which appear close to one of the primary waves 

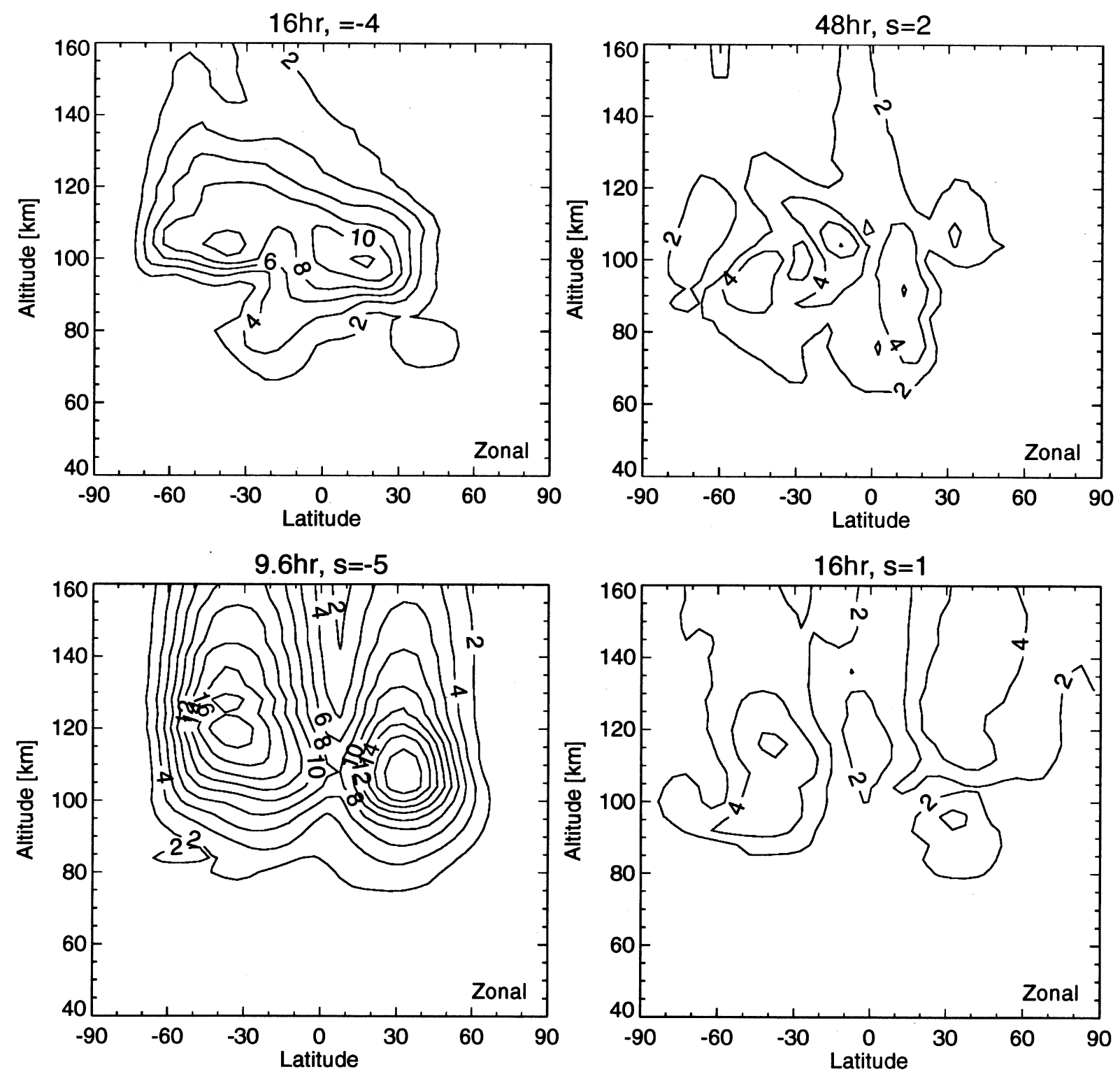

Fig. 8. The amplitude of the $16 \mathrm{~h}$, W4 (top left), 48 h, E2 (top right), $9.6 \mathrm{~h}, \mathrm{~W} 5$ (bottom left) and $16 \mathrm{~h}, \mathrm{E} 1$ (bottom right) are shown for the perturbed zonal wind field.

when the two primary waves are separated significantly in period. Additionally, without the added wavenumber information one is left only with frequency, when using observations from a single ground based site, to determine if an observed wave component is the result of a nonlinear interaction. Some efforts have been made to use the bispectrum (Kim and Powers, 1979; Rüster, 1992; Clark and Bergin, 1997), which is similar to the power spectrum however third order statistics are used rather than second order statistics. These efforts have met with marginal success at best due to the high variance associated with the bispectrum and the phase coherence that exists in tidal and planetary wave signatures. However, given these limitations Manson et al. $(1982,1990)$ have shown that a 9.6 and 16 hour oscillation is present in Saskatoon $\left(52^{\circ} \mathrm{N}, 107^{\circ} \mathrm{W}\right) \mathrm{MF}$ radar data. Furthermore, Manson et al. $(1982,1990)$ postulated that the observed 9.6 and 16 hour oscillations were the re- sult of a nonlinear interaction between the QTDW and the migrating tides. Harris and Vincent (1993) have found evidence, in MF radar observations from Christmas Island $\left(2^{\circ} \mathrm{N}\right.$, $\left.157^{\circ} \mathrm{W}\right)$, for a 16 hour oscillation when the QTDW is present in addition to reduced tidal amplitudes. There is also evidence from London, Ontario $\left(43^{\circ} \mathrm{N}, 81^{\circ} \mathrm{W}\right)$ (Thayaparan et $a l ., 1997 \mathrm{a})$ for the presence of a 16 hour oscillation during January, when the QTDW is at its maximum in the southern hemisphere. Nonlinear modeling studies (Teitelbaum and Vial, 1991) have shown that in some cases the tidal variations observed in Garchy $\left(45^{\circ} \mathrm{N}\right)$ meteor radar data are the result of nonlinear interactions with planetary waves.

As was mentioned above, there appears to be significant circumstantial evidence for the generation of waves in the TIME-GCM via nonlinear interaction between the migrating tides and the QTDW. If this is the case then it is expected that these child waves will obtain energy from their parent waves. 

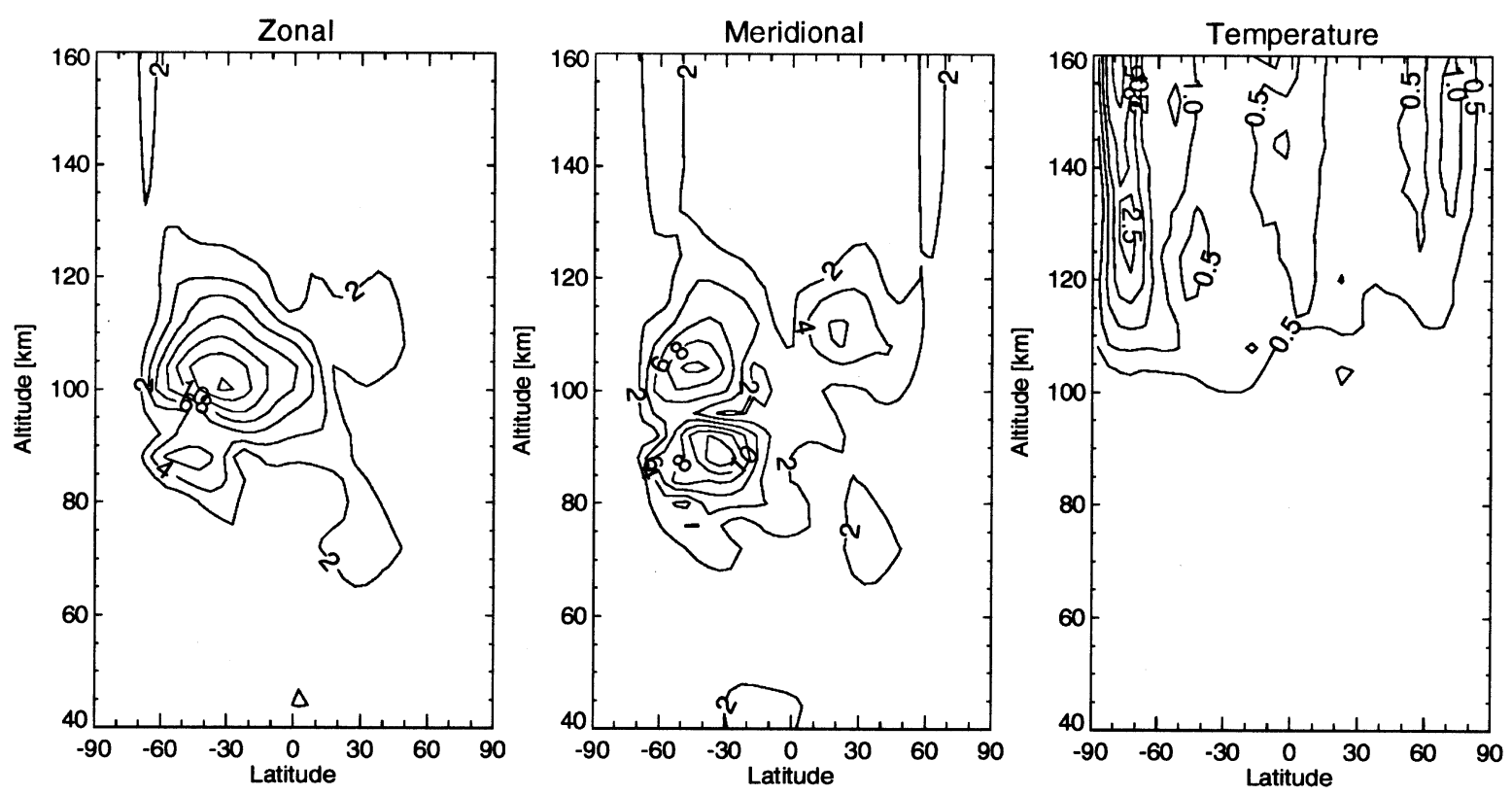

Fig. 9. The amplitude of the zonal wind (left), meridional wind (middle) and temperature (right) for the $24 \mathrm{~h}$, W6 component.

Given all else equal, the amplitude of the parent waves should be reduced due to these nonlinear interactions. This is in fact what we have observed in our TIME-GCM simulations. Similar results have been seen by Norton and Thuburn (1997) and McLandress (1997). Using the United Kingdom Universities Global Atmospheric Modeling Programme (UGAMP) GCM, Norton and Thuburn (1997) observed a correlation between strong QTDW amplitudes and weak tidal amplitudes. This led Norton and Thuburn (1997) to propose that the QTDW may be responsible for reducing the tidal amplitude via nonlinear interaction. Similarly McLandress (1997), using the Canadian Middle Atmosphere Model (CMAM), found a correlation between enhanced planetary wave activity in January and reduce tidal amplitudes.

3.3.1 The $s=6$ westward propagating nonmigrating diurnal tide We have separated our discussion of the (1.0, W6) mode to a separate section because this wave is distinct from all of the other nonlinearly generated waves. First the $(1.0, \mathrm{~W} 6)$ is a third generation 2-2 type wave that is generated as the difference mode from the interaction of two second generation modes. These second generation modes are generated from the interaction of the QTDW with the migrating tides. For instance the interaction between the QTDW and the semidiurnal tide yields the (2.5, W5) and $(1.5$, E1) which interact and yield the (1.0, W6) and (4.0, W4). In fact these type of interaction between the children of interactions between the QTDW and the migrating tides will always yield a (1.0, W6) and a component at $(2 * \mathrm{f}, 2 * \mathrm{~s})$ of the migrating tidal component. The reason why the (1.0, W6) is special is because when the $(1.0, \mathrm{~W} 6)$ and the QTDW interact the result is a $(0.5, \mathrm{~W} 3)$ and a $(1.5, \mathrm{~W} 9)$. Therefore the interaction of the QTDW with the $(1.0$, W6) results in the QTDW. This therefore provides a mechanism for the QTDW and the migrating tides to be coupled. Walterscheid and Vincent (1996) proposed this cascade of nonlinear inter- actions as a mechanism by which the QTDW could be locked in phase to the tidal components. Such an interaction could serve to explain the predisposition of the QTDW to obtain a maximum at nearly the same solar local time from one year to the next. This behavior has been observed in relation to the QTDW (Craig and Elford, 1981; Clark, 1989; Harris, 1994). In this situation the (1.0,W6) would act as a pacemaker driving the QTDW into phase coherence with the migrating tides. Walterscheid and Vincent (1996) have also suggested that the interaction of the $(1.0, \mathrm{~W} 6)$ with the QTDW could served as a mechanism for the dramatic increases in the amplitude of the QTDW that can occur over short time periods.

One might suppose that the $(1.0, \mathrm{~W} 6)$ is the result of a nonlinear interaction between the QTDW and itself. However, the self-interaction for low-frequency waves of moderate amplitudes is nearly nonexistent (Teitelbaum and Vial, 1991). This is because for transverse waves, such as the tides and the QTDW, the advective terms are small except for very large amplitude waves. It may be possible that a QTDW amplitude of $80 \mathrm{~m} \mathrm{~s}^{-1}$ is sufficient to violate this assumption. At this point we cannot prove nor disprove this premise, however self-interaction does appear to be unlikely.

Figure 9 shows the vertical and latitudinal structure of the $(1.0, \mathrm{~W} 6)$ mode for days $14-16$ of the perturbed TIMEGCM model runs. These results were determined from a two-dimensional linear least squares fit. The zonal (left) and meridional (middle) wind fields exhibit significant amplitudes in the southern hemisphere lower-thermosphere. For example, the zonal wind field indicates amplitudes of 14 $\mathrm{m} \mathrm{s}^{-1}$ near $30^{\circ} \mathrm{S}$ at $100 \mathrm{~km}$ while the meridional wind field indicates amplitudes of $12 \mathrm{~m} \mathrm{~s}^{-1}$ and $10 \mathrm{~m} \mathrm{~s}^{-1}$ at $90 \mathrm{~km}, 35^{\circ} \mathrm{S}$ and $105 \mathrm{~km}, 45^{\circ} \mathrm{S}$ respectively. There is some indication of a small enhancement in the northern hemisphere meridional amplitude. In contrast the temperature field exhibits virtually no change below $100 \mathrm{~km}$ and only minor changes 
$(2.5 \mathrm{~K})$ above $100 \mathrm{~km}$. The fact that the largest wind amplitudes occur in the southern hemisphere lower-thermosphere may suggest that energy could be transferred from the (1.0, W6) to the QTDW efficiently.

\section{Concluding Remarks}

We have presented results from a set of numerical experiments relating to the QTDW in the middle atmosphere horizontal wind and temperature fields. These experiments were conducted using the NCAR TIME-GCM. Our results indicate that the structure of the QTDW wave during January is relatively insensitive to the exact period of forcing at the lower-boundary, which would indicate a broad resonant type response. However model runs conducted for Decmeber and February resulted in virtually no lower-thermospheric response, indicating the structure of the QTDW in the middle atmosphere is directly related to the zonal mean zonal wind field. This has also been previously noted by Salby (1981a) and Hagan et al. (1993). The structure of the QTDW in the TIME-GCM is in qualitative agreement with both GSWM model simulations and observations. The most signifcant difference between the model simulations and observations is the lack of an equatorial response in the lower-thermosphere. The TIME-GCM results also show the presence of a lowerthermospheric response which is out-of-phase with the mesospheric response. A similar structure has been observed (Ward et al., 1996; Zhou et al., 1997) and modeled (Meyer, 1994). Currently it appears that this peak is the result of gravity waves interacting with the QTDW.

In addition to interacting with gravity waves, it also appears that the QTDW is interacting both with the mean flow and the migrating tides. All three of these can be catagorized as nonlinear interactions. Difference fields computed for the zonal mean winds and temperature, indicate that over the course of our simulations the zonal mean state has changed. Similar difference fields computed for our base case (w/o QTDW) indicate virtually no change in the zonal mean state. Comparison of our results with those derived from UARS measurements (Lieberman, 1999) indicate some significant differences. Lieberman (1999) estimated the zonal mean accelerations due to the QTDW to be primarily in the northward and westward directions while our results are significantly more complicated. It is expected that the added complexity in the TIME-GCM results is because the direct wave driving effects have not been separated from gravity wave and consituent transport effects.

The most dramatic results which have come from our simulations are the clear evidence for nonlinear interactions between the QTDW and the migrating tides. Not only do we see a significant decrease in tidal amplitudes when the QTDW is present but numerous waves are generated which are not present when the QTDW is absent. It has been shown that all of the waves present in the spectra when the QTDW is included at the model lower-boundary can be tracked back to a nonlinear interaction between the migrating tides and the QTDW. More importantly, we have verified the existence of a (1.0, W6) mode which was proposed by Walterscheid and Vincent (1996) as a mechanism for locking the QTDW in local time.
Acknowledgments. The authors thank Professor Jeffrey Forbes, Professor Robert Vincent, Dr. Richard Walterscheid, Dr. Francios Vial and Dr. Ruth Lieberman for their stimulating discussions. We would also like to thank Dr. Arthur Richmond and the reviewers for their valuable comments on this manuscript. This research has been supported by the National Science Foundation CEDAR program ATM-9612920. The efforts of Dr. M. E. Hagan were support by the NSF CEDAR program. Partial support has also been provided from the NASA Space Physics Theory Program (S-97239-E). The National Center for Atmospheric Research is supported by the National Science Foundation.

\section{References}

Andrews, D. G., J. R. Holton, and C. B. Leovy, Middle Atmosphere Dynamics, 489 pp., Orlando, FL, Academic Press, 1987.

Avery, S. K., R. A. Vincent, A. Phillips, A. H. Manson, and G. J. Fraser, High-latitude tidal behavior in the mesosphere and lower thermosphere, J. Atmos. Terr. Phys., 51(7/8), 595-608, 1989.

Boville, B. A., Middle atmosphere version of ccm2 (maccm2): Annual cycle and interannual variability, J. Geopys. Res., 100(D5), 9017-9039, 1995.

Burks, D. and C. Leovy, Planetary waves near the mesospheric easterly jet, Geophys. Res. Lett., 13(3), 193-196, 1986.

Charney, J. G. and P. G. Drazin, Propagation of planetary-scale disturbances from the lower into the upper atmosphere, J. Geophys. Res., 66(1), 83$109,1961$.

Clark, R. R., Meteor wind measurements at Durham, New Hampshire $\left(43^{\circ} \mathrm{N}\right.$, $\left.71^{\circ} \mathrm{W}\right)$, J. Atmos. Sci., 32, 1689-1693, 1975.

Clark, R. R., The quasi 2-day wave at Durham $\left(43^{\circ} \mathrm{N}\right)$ : Solar magnetic effects, J. Atmos. Terr. Phys., 51, 617-622, 1989.

Clark, R. R. and J. S. Bergin, Bispectral analysis of mesosphere winds, $J$. Atmos. Terr. Phys., 59(6), 629-639, 1997.

Clark, R. R. and J. E. Salah, Propagation of the solar semidiurnal tide in the mesosphere and lower-thermosphere at midlatitudes, J. Geophys. Res., 96, 1129-1133, 1991

Clark, R. R., A. C. Current, A. H. Manson, C. E. Meek, S. K. Avery, S. E. Palo, and T. Aso, Hemispheric properties of the two-day wave from mesosphere-lower-thermosphere radar observations, J. Atmos. Terr. Phys., 56(10), 1279-1288, 1994.

Coy, L., A possible 2-day oscillation near the tropical stratopause, J. Atmos. Sci., 36, 1615-1618, 1979.

Craig, R. L. and W. G. Elford, Observations of the quasi 2-day wave near $90 \mathrm{~km}$ altitude at Adelaide $\left(35^{\circ} \mathrm{S}\right)$, J. Atmos. Terr. Phys., 43, 1051-1056, 1981 .

Craig, R. L., R. A. Vincent, G. J. Fraser, and M. J. Smith, The quasi 2day wave in the southern hemisphere mesosphere, Nature, 287, 319-320, 1980

Dunkerton, T. J., Theory of the mesopause semiannual oscillation, J. Atmos. Sci., 39(12), 2681-2690, 1982

Forbes, J. M., M. E. Hagan, S. Miyahara, F. Vial, A. H. Manson, C. E. Meek, and Y. I. Portnyagin, Quasi 16-day oscillation in the mesosphere and lower thermosphere, J. Geophys. Res., 100(D5), 9149-9163, 1995.

Fritts, D. C. and J. R. Isler, Mean motions and tidal and two-day structure and variability in the mesosphere and lower thermosphere over Hawaii, J. Atmos. Sci., 51(14), 2145-2164, 1994

Fritts, D. C., J. R. Isler, R. S. Lieberman, M. D. Burrage, D. R. Marsh, T. Nakamura, T. Tsuda, R. A. Vincent, and I. M. Reid, Two-day wave structure and mean flow interactions observed by radar and High Resolution Doppler Imager, J. Geophys. Res., 104, 3953-3969, 1999.

Geller, M., V. A. Yudin, B. V. Khattatov, and M. E. Hagan, Modeling the diurnal tide with dissipation derived from UARS/HRDI measurements, Ann. Geophys., 15(9), 1198-1204, 1997.

Glass, M., J. L. Fellous, M. Massebeuf, A. Spizzichino, I. A. Lysenko, and Y. I. Portniagin, Comparison and interpretation of the results of simultaneous wind measurements in the lower thermosphere at Garchy (France) and Obninsk (U.S.S.R.) by meteor radar technique, J. Atmos. Terr. Phys., 37 1077-1087, 1975.

Hagan, M. E., Comparative effects of migrating solar sources on tidal signatures in the middle and upper atmosphere, J. Geophys. Res., 101, 21,21321,222, 1996

Hagan, M. E., J. M. Forbes, and F. Vial, Numerical investigation of the propagation of the quasi-two-day wave into the lower thermosphere, $J$ Geophys. Res., 98, 23,193-23,205, 1993.

Hagan, M. E., J. M. Forbes, and F. Vial, On modeling the migrating solar tides, Geophys. Res. Lett., 22(8), 893-896, 1995. 
Hagan, M. E., J. M. Forbes, and C. McLandress, Diurnal tidal variability in the upper mesosphere and lower thermosphere, Ann. Geophys., 15(9), 1176-1186, 1997.

Hagan, M. E., M. D. Burrage, J. M. Forbes, J. Hackney, W. J. Randel, and X. Zhang, GSWM-98: Results for migrating solar tides, J. Geophys. Res., 104, 6813-6827, 1999.

Harris, T. J., A long-term study of the quasi 2-day wave in the middle atmosphere, J. Atmos. Terr. Phys., 56(5), 569-579, 1994.

Harris, T. J. and R. A. Vincent, The quasi-2-day wave observed in the equatorial middle atmosphere, J. Geophys. Res., 98, 10,481-10,490, 1993.

Hays, P. B., V. J. Abreu, M. E. Dobbs, D. A. Gell, H. J. Grassl, and W. R. Skinner, High-resolution Doppler imager on the Upper Atmosphere Research Satellite, J. Geophys. Res., 98, 10,713-10,723, 1993.

Hedin, A. E., Extensions of the MSIS thermosphere model into the middle and lower atmosphere, J. Geophys. Res., 96(A2), 1159-1172, 1991.

Hirota, I., Equatorial waves in the upper stratosphere and mesosphere in relation to the semiannual oscillation of the zonal wind, J. Atmos. Sci., 35(4), 714-722, 1978.

Hunt, B. G., The 2-day wave in the middle atmosphere as simulated in a general circulation model extending from the surface to $100 \mathrm{~km}, J$. Atmos Terr. Phys., 43(11), 1143-1154, 1981.

Kal'chanko, B. V. and S. V. Bulgakov, Study of periodic components of wind velocity in the lower thermosphere above the equator, Geomagn. Aeron., 13, 955-956, 1973 .

Kiehl, J. T., J. J. Hack, G. B. Bonan, B. A. Boville, D. L. Williamson, and P. J. Rasch, The national center for atmospheric research community climate model: CCM3, J. Climate, 11, 1131-1149, 1998.

Kim, Y. C. and E. J. Powers, Digital bispectral analysis and its applications to nonlinear wave interactions, IEEE Trans. Plasma Sci., 7(2), 120-131, 1979.

Lieberman, R. S., Eliassen-palm fluxes of the two-day wave, J. Atmos. Sci., 1999 (in press).

Manson, A. H., C. E. Meek, J. B. Gregory, and D. K. Chakrabarty, Fluctuations in tidal (24-12 h) characteristics and oscillations ( $5 \mathrm{~h}-5 \mathrm{~d})$ in the mesosphere and lower thermosphere at Saskatoon $\left(52^{\circ} \mathrm{N}, 107^{\circ} \mathrm{W}\right)$, 1979-1981, Planet. Space Sci., 30, 1283, 1982.

Manson, A. H., C. E. Meek, H. Teitelbaum, F. Vial, R. Schminder, D. Kürschner, M. J. Smith, G. J. Fraser, and R. R. Clark, Climatologies of semi-diurnal and diurnal tides in the middle atmosphere $(70-110 \mathrm{~km})$ at middle latitudes $\left(40-55^{\circ}\right)$, J. Atmos. Terr. Phys., 51, 579-593, 1989.

Manson, A. H., C. E. Meek, R. A. Vincent, R. L. Craig, A. Phillips, G. J. Fraser, M. J. Smith, J. L. Fellous, M. Massebeuf, E. L. Flemming, and S. Chandra, Comparison between reference atmosphere winds and radar winds from selected locations, Adv. Space Res., 10(12), 233-244, 1990.

McLandress, C., Seasonal variability of the diurnal tide: Results from the Canadian middle atmosphere general circulation model, J. Geophys. Res., 102, 29,747-29,764, 1997.

McLandress, C., C. Y. Rochon, G. G. Shepherd, B. H. Solheim, G. Thullier, and F. Vial, The meridional wind component of the thermospheric tide observed by WINDII on UARS, Geophys. Res. Lett., 21, 2417-2420, 1994.

McLandress, C., G. G. Shepherd, and B. H. Solheim, Combined mesosphere/thermosphere winds using WINDII and HRDI data from the Upper Atmosphere Research Satellite, J. Geophys. Res., 101, 10,441-10,453, 1996

Meek, C. E., A. H. Manson, S. J. Franke, W. Singer, P. Hoffman, R. R. Clark, T. Tusda, T. Nakamura, M. Tsutsumi, M. Hagan, D. C. Fritts, J. Isler, and Y. I. Portnyagin, Global study of northern hemisphere quasi-2day wave events in recent summers near $90 \mathrm{~km}$ altitude, J. Atmos. Terr. Phys., 58(13), 1401-1411, 1996.

Meyer, C. K., Gravity wave-tidal and gravity wave-planetary wave interactions in the mesosphere and lower thermosphere, Ph.D. thesis, Univ. of Colo., Boulder, 1994.

Muller, H. G., Long-period meteor wind oscillations, Phil. Trans. R. Soc. London Ser. A, 271, 585-598, 1972.

Norton, W. A. and J. Thuburn, The two-day wave in a middle atmosphere gcm, Geophys. Res. Lett., 23, 2113-2116, 1996.

Norton, W. A. and J. Thuburn, The mesosphere in the extended UGAMP GCM, in Gravity Wave Processes and Their Parameterizations in Global Climate Models, edited by K. Hamilton, pp. 383-401, Springer Verlag, 1997.

Palo, S. E. and S. K. Avery, Mean winds and the semiannual oscillation in the mesosphere and lower thermosphere at Christmas Island, J. Geophys. Res., 98, 20,385-20,400, 1993.

Palo, S. E. and S. K. Avery, Observations of the meridional quasi two-day wave in the mesosphere and lower thermosphere at Christmas Island, in The Upper Mesosphere and Lower Thermosphere: A Review of Experiment and Theory, edited by R. M. Johnson and T. L. Killeen, pp. 101-110, American Geophysical Union, Geophysical Monograph 87, 1995.

Palo, S. E. and S. K. Avery, Observations of the quasi-two-day wave in the middle and lower atmosphere over Christmas Island, J. Geophys. Res. 101(D8), 12,833-12,846, 1996.

Palo, S. E., M. E. Hagan, C. E. Meek, R. A. Vincent, M. D. Burrage, C. McLandress, S. J. Franke, W. Ward, R. R. Clark, P. Hoffman, R. Johnson, D. Kuerschner, A. H. Manson, D. Murphy, T. Nakamura, Y. I. Portnyagin, J. E. Salah, R. Schminder, W. Singer, T. Tsuda, T. S. Virdi, and Q. Zhou, An intercomparison between the GSWM, UARS, and ground based radar observations: A case-study in January 1993, Ann. Geophys., 15, 1123 1141, 1997.

Palo, S. E., R. G. Roble, and M. E. Hagan, Time-gcm results for the quasitwo-day wave, Geophys. Res. Lett., 25, 3783-3786, 1998.

Pfister, L., Baroclinic instability of easterly jets with applications to the summer mesosphere, J. Atmos. Sci., 42(4), 313-330, 1985.

Plumb, R. A., Baroclinic instability of the summer mesosphere: A mechanism for the quasi-two-day wave?, J. Atmos. Sci., 40, 262-270, 1983.

Plumb, R. A., R. A. Vincent, and R. L. Craig, The quasi-2-day wave event of January 1994 and its impact on the mean mesospheric circulation, $J$. Atmos. Sci., 44, 3030-3036, 1987.

Randel, W. J., Observations of the 2-day wave in NMC stratospheric analysis, J. Atmos. Sci., 51(2), 306-313, 1994.

Roble, R. G. and E. C. Ridley, A thermosphere-ionosphere-mesosphereelectrodynamics general circulation model (TIME-GCM): Equinox solar cycle minimum simulations (30-500 km), Geophys. Res. Lett., 21, 417420, 1994.

Roble, R. G., E. C. Ridley, A. D. Richmond, and R. E. Dickinson, A coupled thermosphere/ionosphere general circulation model, Geophys. Res. Lett. 15, 1325-1328, 1988

Rodgers, C. D. and A. J. Prata, Evidence for a traveling two-day wave in the middle atmosphere, J. Geophys. Res., 86, 9661-9664, 1981.

Rüster, R., VHF radar observations in the summer polar mesosphere indicating nonlinear interaction, Adv. Space Res., 12(10), 85-88, 1992.

Salby, M. L., Rossby normal modes in nonuniform background configurations I, Simple fields, J. Atmos. Sci., 38, 1803-1826, 1981a.

Salby, M. L., Rossby normal modes in nonuniform background configurations II, Equinox and solstice conditions, J. Atmos. Sci., 38, 1827-1840, 1981b.

Salby, M. L., Sampling theory for asynoptic satellite observations. Part I: Space-time spectra, resolution and aliasing, J. Atmos. Sci., 39, 25772600, 1982

Salby, M. L. and R. G. Roper, Long-period oscillations in the meteor region, J. Atmos. Sci., 37, 237-244, 1980.

Teitelbaum, H. and F. Vial, On tidal variability induced by nonlinear interaction with planetary waves, J. Geophys. Res., 96, 14,169-14,178, 1991

Thayaparan, T., W. K. Hocking, and J. MacDougal, Amplitude, phase and period variations of the quasi 2-day wave in the mesosphere and lower thermosphere over London Ontario ( $\left.43^{\circ} \mathrm{N}, 81^{\circ} \mathrm{W}\right)$, during 1993 and 1994 , J. Geophys. Res., 102, 9461-9478, 1997a.

Thayaparan, T., W. K. Hocking, J. MacDougal, A. H. Manson, and C. E. Meek, Simultaneous observations of the 2-day wave at London Ontario $\left(43^{\circ} \mathrm{N}, 81^{\circ} \mathrm{W}\right)$ and Saskatoon $\left(52^{\circ} \mathrm{N}, 107^{\circ} \mathrm{W}\right)$ near $91 \mathrm{~km}$ altitude during the two years 1993 and 1994, Ann. Geophys., 15, 1324-1339, 1997b.

Tsuda, T., S. Kato, and R. A. Vinent, Long period wind oscillations observed by the Kyoto meteor radar and comparisons of the quasi-2-day wave with Adelaide HF radar observations, J. Atmos. Terr. Phys., 50, 225-230, 1988.

Vincent, R. A., T. Tsuda, and S. Kato, Asymmetries in mesospheric tidal structure, J. Atmos. Terr. Phys., 51, 663-671, 1989.

Walterscheid, R. and R. Vincent, Tidal generation of the phase-locked 2-day wave in the southern hemisphere summer by wave-wave interactions, $J$ Geophys. Res., 101, 26,567-26,576, 1996.

Ward, W. E., D. Y. Wang, B. H. Solheim, and G. G. Shepherd, Observations of the two-day wave in WINDII data during January, 1993, Geophys. Res. Lett., 23, 2923-2926, 1996.

Wu, D. L., P. B. Hays, W. R. Skinner, A. R. Marshall, M. D. Burrage, R. S. Lieberman, and D. A. Ortland, Observations of the quasi 2-day wave from the high resolution Doppler imager on UARS, Geophys. Res. Lett., 20(24), 2853-2856, 1993.

Wu, D. L., P. B. Hays, and W. R. Skinner, A least squares method for spectral analysis of space-time series, J. Atmos. Sci., 52(20), 3501-3511, 1995.

Wu, D. L., E. F. Fishbein, W. G. Reid, and J. W. Waters, Excitation and evolution of the quasi-2-day wave observed in UARS/MLS temperature 
measurements, J. Atmos. Sci., 53(5), 728-738, 1996.

Yudin, V. A., B. V. Khattatov, M. A. Geller, D. A. Ortland, C. McLandress, and G. G. Shepherd, Thermal tides and studies to tune the mechanistic tidal model using UARS observations, Ann. Geophys., 15(9), 1205-1220, 1997.

Zhou, Q. H., M. P. Sulzer, and C. A. Tepley, An analysis of tidal and planetary waves in the neutral winds and temperature observed at the E-region, $J$. Geophys. Res., 102(A6), 11,491-11,505, 1997.

S. E. Palo (e-mail: palo@colorado.edu), R. G. Roble, and M. E. Hagan 